IZA DP No. 7729

The Ins and Outs of Top Income Mobility

Rolf Aaberge

Anthony B. Atkinson

Jørgen Modalsli

November 2013 


\title{
The Ins and Outs of Top Income Mobility
}

\author{
Rolf Aaberge \\ Statistics Norway, \\ ESOP, University of Oslo and IZA \\ Anthony B. Atkinson \\ Nuffield College, Oxford \\ Jørgen Modalsli \\ Statistics Norway
}

Discussion Paper No. 7729
November 2013

\author{
IZA \\ P.O. Box 7240 \\ 53072 Bonn \\ Germany \\ Phone: +49-228-3894-0 \\ Fax: +49-228-3894-180 \\ E-mail: iza@iza.org
}

\begin{abstract}
Any opinions expressed here are those of the author(s) and not those of IZA. Research published in this series may include views on policy, but the institute itself takes no institutional policy positions. The IZA research network is committed to the IZA Guiding Principles of Research Integrity.

The Institute for the Study of Labor (IZA) in Bonn is a local and virtual international research center and a place of communication between science, politics and business. IZA is an independent nonprofit organization supported by Deutsche Post Foundation. The center is associated with the University of Bonn and offers a stimulating research environment through its international network, workshops and conferences, data service, project support, research visits and doctoral program. IZA engages in (i) original and internationally competitive research in all fields of labor economics, (ii) development of policy concepts, and (iii) dissemination of research results and concepts to the interested public.
\end{abstract}

IZA Discussion Papers often represent preliminary work and are circulated to encourage discussion. Citation of such a paper should account for its provisional character. A revised version may be available directly from the author. 
IZA Discussion Paper No. 7729

November 2013

\section{ABSTRACT}

\section{The Ins and Outs of Top Income Mobility}

This paper is concerned with the question of whether top income earners are permanently there or only temporarily receive the highest incomes. How much mobility is there at the top of the income distribution, and how has mobility changed over time? The paper makes both a methodological and an empirical contribution to answering these questions. The first part of the paper introduces a family of top income mobility measures based on differences in average annual incomes of top income earners in short-term and long-term distributions of income. Norwegian income tax records are then employed to study top income mobility in Norway since 1967. The results reveal low levels of top income mobility, but a relatively large increase in mobility starting at the same time as the income shares of the top income receivers started to increase around 1990.

JEL Classification: J31, E24, D63, N34

Keywords: top income shares, income mobility, inequality

Corresponding author:

Rolf Aaberge

Research Department

P.O. Box 8131 Dep.

Statistics Norway

0033 Oslo

Norway

E-mail: rolf.aaberge@ssb.no 


\section{Introduction}

Concerns about the rising share of top incomes in many countries are often countered with the view that the composition of the top income classes is constantly changing. Each year there are new entrants to the top 1 per cent and there are corresponding exits. Top incomes might not necessarily translate into high concentration of power. Calculation of top incomes from annual cross-sections does not reveal the extent of concentration over time. As increased economic liberalization was an important driver of increases in top income shares after 1980, it could be that there was, in fact, a much lower increase in the concentration of "economic power", if income volatility and income mobility increased. In the famous quotation of Joseph Schumpeter, the class "resembles a hotel, or omnibus, always full, but always of different people". The reference of an "omnibus" dates this quotation and we have to ask whether this is indeed true today. How much mobility is there in the top income groups? How much difference would it make to measured top income shares if incomes were averaged over several years? There have been relatively few studies of top income mobility. This reflects the fact that many studies are based on cross-section data. In this paper we exploit the rich register data held by Statistics Norway covering the period 1967 to 2011 to explore the pattern of mobility at the top of the income distribution. There has equally been little discussion of the theory of mobility measurement applied specifically to top incomes, and in this paper we propose a new approach.

In the remainder of this introduction, we summarise the evidence about the evolution of top income shares in Norway, updating the series in Aaberge and Atkinson (2010) to 2011, and adding information covering the period 1892 to 1903. It is however the period since 1967 that is our primary focus and that forms the basis for our results on top income mobility. Before presenting this evidence, we propose in Section 2 of the paper a general framework in terms of the "top income mobility curve" for comparing income distributions with regard to the extent of income mobility, when mobility is defined to be associated with the equalization of permanent income. Section 3 shows how the top income mobility curve provides evidence about the extent of mobility in top incomes in Norway and how mobility has changed over the period 1967 to the present. In order to understand better who enters and leaves the top income groups, Section 4 examines mobility over the life-cycle and across cohorts. Section 5 considers the very special episode in 2005 when top income shares in Norway spiked as a result of the pre-announcement of a permanent dividend tax implemented in 2006. This tax reform gave strong incentives for owner-managers of closely held firms to increase dividends in 2005 (the tax on dividends was to be increased in 2006 from 0 to 28 per cent). The share of the top 1 per cent rose by some 5 percentage points in 2005 and then halved in 2006 . There was a large turnover in the 
composition of the top income groups in that year, and we ask who it was who took advantage of this pre-announcement. The conclusions are summarised in Section 6.

\subsection{Top income shares}

The evolution of the shares of top incomes in Norway was explored by Aaberge and Atkinson (2010) using data that start as far back as 1875. The series of the top of the income distribution covers a period when Norway industrialised and then became oil-rich. While there are not data for all years, the results cover more than a century and a quarter. The reader may wonder how far it is possible to construct a consistent series over time, and the results certainly need to be interpreted carefully in the light of changing economic and social circumstances, but there is continuity in the basic source: the data collected as part of administering the municipal and central government income tax.

Before 1967, the information comes from tabulated income data; see Aaberge and Atkinson (2010) for a complete description. The tables were published in various publications of income distribution and/or tax collection. Since the construction of the series in Aaberge and Atkinson (2010), a number of new tabulations have been discovered, providing further information about the period 1888 to 1903 . The sources and methods are described in the Appendix. ${ }^{1}$

Starting in 1967, we use individual micro data from the national tax register, covering all individuals working and residing in Norway. The pre-tax income variable is commonly referred to as "net income", and was the income concept used for income taxation. The difference from the actual income (both labour and other income) paid to an individual is some minor basic deductions. ${ }^{2}$ We take our population to be all resident individuals aged 16 and above, including those with zero income. The control total for income is based on the National Accounts after 1946, and on historical statistics before this, as described in the Appendix.

\footnotetext{
${ }^{1}$ We are most grateful to Facundo Alvaredo for pointing out that these data exist.

${ }^{2}$ It should be noted that the usage of "net income" depresses top income shares by around 1.5 percentage points compared to gross income, as deductions are relatively more important for lower incomes. However, for the post-1993 period, where we also have data for gross incomes, both the trends and the mobility indices (as explained in Section 3) are virtually identical across the two definitions.
} 


\subsection{Development of top income shares 1875 to 2011}

Figure 1 shows the development of top income shares in Norway since 1875, incorporating the new estimates for the late nineteenth century and taking the data series up to 2011.

Figure 1. Top income shares, 1875-2011

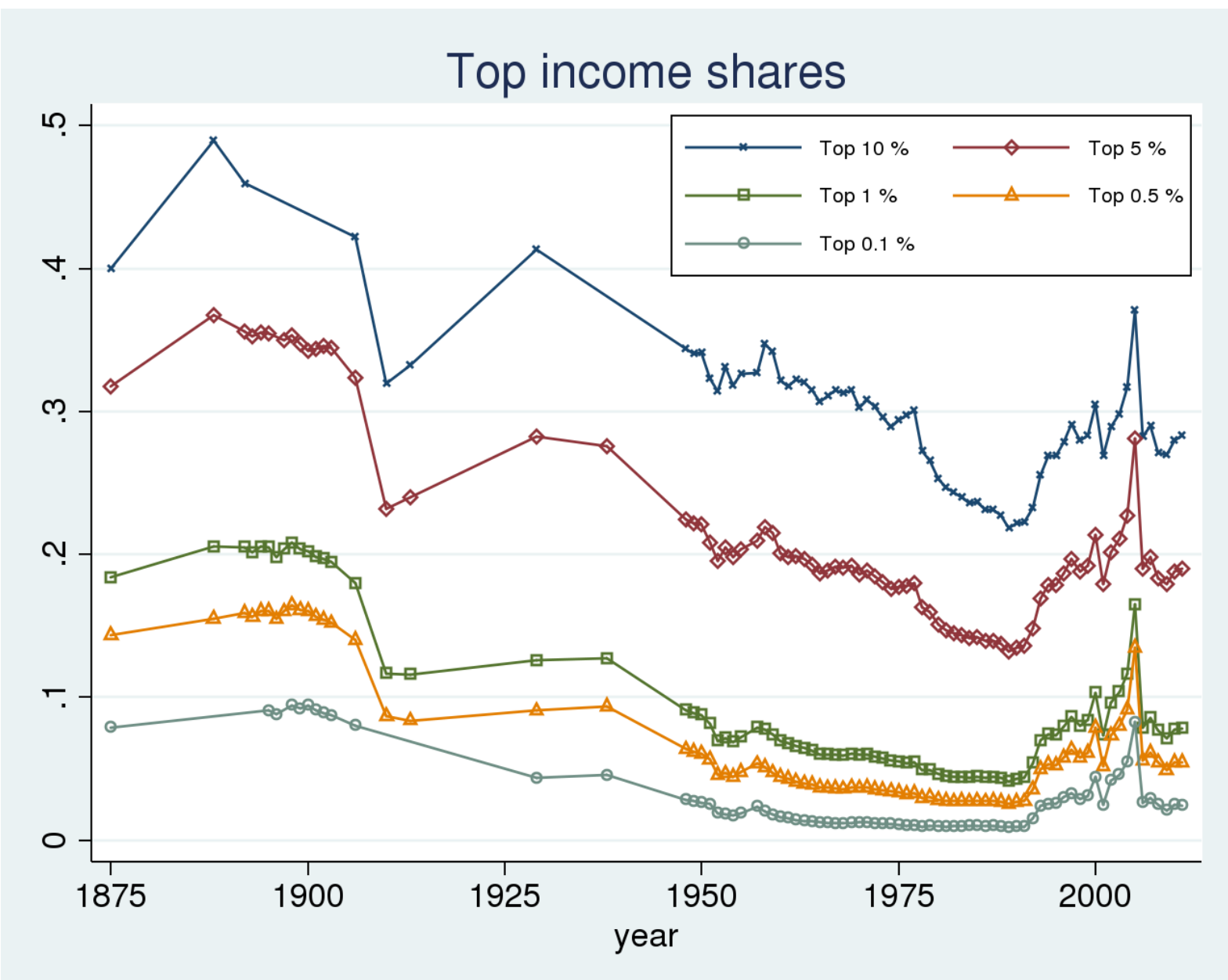

Top income shares were relatively high in the late nineteenth century. In that period Norway was still predominantly an agricultural society; more than half of the economically active population worked in agriculture or fisheries. In 1888, the top 10 per cent had 48 per cent of the total income, while the top 0.1 per cent got around 7.5 per cent. There is a decrease in top incomes over the last decades of the nineteenth century. A consistent series from 1898 to 1903 ends in 8.7 per cent for the top 0.1 per cent in 1903; data from 1906 gives 42 per cent to the top decile. After 1906, top incomes shares fell rapidly, which might partly be due to the structural change (agricultural employment fell from $46 \%$ in 1875 to $28 \%$ in 1920) and the rapid inflation (the price level tripled from 1914 to 1920) during this period. Sadly, the data points are far apart in the twenties and thirties, but from 1920, Norway 
followed a deflationary policy, and there appears to have been an increase for the larger top income groups, with share of the top $10 \%$ peaking at $41 \%$ in 1929.

Between the end of the Second World War and the late 1980s, top income shares declined steadily. The lowest point was reached in 1989, when the top $10 \%$ income share was 22 per cent and the top $0.1 \%$ share was $0.61 \%$. This period is characterised by high economic growth, an extension of the social security system and improved access to education, combined with relatively tightly regulated capital markets. The financial deregulation initiated in 1984 did not lead immediately to a rise in top shares, but its distributional impact was probably postponed by the economic recession and the related Norwegian banking crisis of 1988 to 1992. As the economy picked up speed from around 1990 forward, there is a steep increase in top income shares. At this point, there is also a series of tax reforms; from 1986 to 1992, the marginal tax on capital income was gradually reduced to a flat rate of $28 \%$. This increased the incentives to realise dividends and capital incomes and led to a rise in the top income shares.

Two peaks for the top income shares in the previous decade are worth special mention. First, in 2000/2001, there was an increased tax on dividends. Anticipating the increase, there is a peak in top income shares in 2000 (as dividends were realised before the reform) and a corresponding fall in 2001. Second, in 2005/2006, the tax reform was again changed. The extreme distributional response to the reform in 2006 brought top income shares back to levels not seen since the early twentieth century. Except for the distributionally turbulent years of 2000/2001 and 2005/2006, top income shares have stabilized at the levels of the late 1990s.

Since our concern in this paper is with movements in and out of the top income groups, it is salutary to compare the top income shares with those at the bottom of the distribution. Figure 2 shows the share of the top $1 / 2$ per cent (as in Figure 1) and the proportion of the population that would have to be included, starting from the bottom, in order that this latter group had the same share of total income. So that in 1970 , for example, the share of the bottom $1 / 2$ per cent was some 3.7 per cent of total income, but this share was equal to that of the bottom 46 per cent. It should be borne in mind that a sizeable number of people had zero incomes, since we are including all persons aged 16 and over, but it is nonetheless striking that there were 92 people for every 1 person in the top $1 / 2$ per cent. By 1990 , the figure had fallen to some 22 per cent, but it then rose to around 29 per cent by 2011. 
Figure 2. Income share of the top $5 \%$ and the bottom population needed to reach the same income share

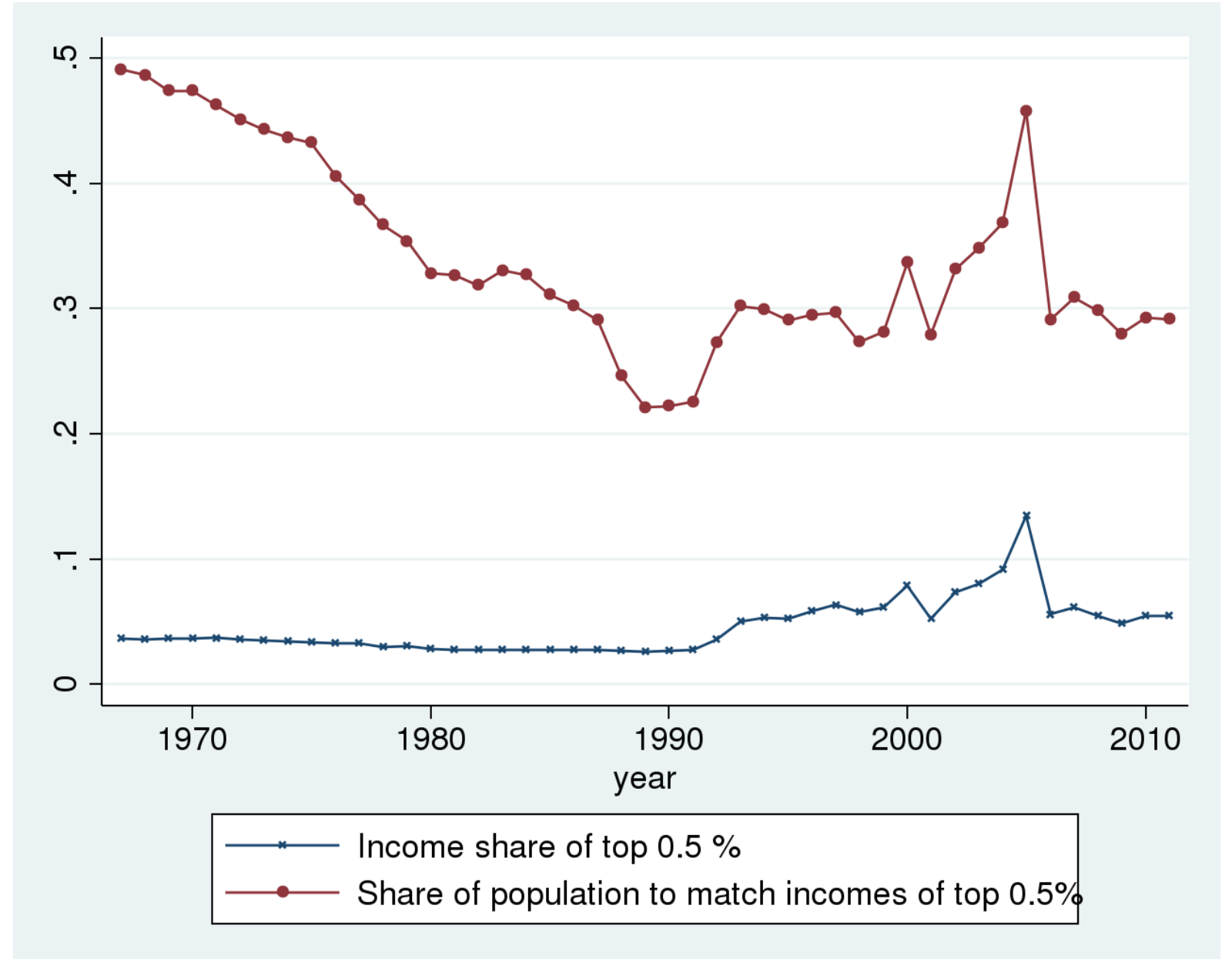

\section{A framework for measuring top income mobility}

Mobility at the top is typically described in terms of people moving in and out of the top x per cent. Do people change rank? For example, Auten et al (2013) examine the persistence of individuals in the top 1 per cent of U.S. taxpayers (whether they stay in the same group), and find no large changes in the 1991-2009 period. It is clear however that the implications for income inequality - our concern here - depend not only on changes in rank but also on the extent of income change. In a country where incomes are grouped closely together, a small increase may be sufficient to take a person into the top x per cent, and this country may therefore exhibit apparently high mobility in terms of ranks. It is therefore necessary to consider both the correlation of ranks over time and the marginal distributions of income.

In order to provide a framework, we start from the position that top income mobility is defined in terms of the equalization of permanent income. There are several reasons for being interested in 
measuring mobility, but this particular formulation has direct links with the measurement of income inequality. In this approach, we are following the lead of Shorrocks (1978), who defines mobility as "the extent to which the income distribution is equalised as the accounting period is extended" (1978, page 378). Shorrocks' mobility measure defines "no mobility" as a state where relative incomes between all individuals are constant. Aaberge et al (2002) redefine the concept of "no mobility" to be that of constant rankings, instead of relative incomes. Their measure captures more closely a definition of mobility from whether individuals' paths of income cross, rather than the degree of correlation between these paths. (In addition, it allows for a mobility measure based on the Gini coefficient.) However, as indicated by Aaberge and Mogstad (2013), the methods proposed by Shorrocks (1978) and Aaberge et al. (2002) are not in accord with a mobility concept where higher mobility means that changes in the relative incomes of individuals occur more frequently or are greater in magnitude. In particular, they show that if cross-sectional inequality is low then even minor changes in relative income over time may translate into high income mobility. Thus, since the traditional mobility measures do not adequately capture the concepts they were designed to measure, namely the share of cross-sectional inequality that is transitory, Aaberge and Mogstad (2013) introduced a formal representation of income mobility as an equalizer of permanent income.

When mobility is defined as an equalizer of permanent income it is attractive to develop methods for measuring mobility by proceeding along similar lines to the measurement of income inequality. Thus, in order to compare distributions with respect to mobility Aaberge and Mogstad (2013) introduced the mobility curve, based on the comparison of two Lorenz curves:

$$
M(u)=L_{Z}(u)-L_{Z_{R}}(u),
$$

where $L_{Z}$ and $L_{Z_{R}}$ denotes the Lorenz curves for the distribution $F_{Z}$ of the observed permanent income $Z$, defined as the total income over all $r$ periods, and the distribution $F_{Z_{R}}$ of the hypothetical reference permanent income $Z_{R}$ when there is no mobility, so that no one changes rank. The reference distribution is formed by assigning the lowest income in every period to the poorest individual in the first period, the second lowest to the second poorest, and so on. Accordingly, the distribution of $Z_{R}$ is designed on the condition that the marginal period-specific distributions are kept fixed. The mobility measure, $M(u)$, may be seen as the difference between the Lorenz ordinate for permanent income and the average Lorenz ordinate for each period's distribution.

Since $L_{Z}$ can be attained from $L_{Z_{R}}$ by a sequence of Pigou-Dalton equalizing permanent income transfers that keep the period-specific distributions unchanged, it follows that $L_{Z}(u) \geq L_{Z_{R}}(u)$ 
for all $u \in[0,1]$, and moreover that $L_{Z}(u)=L_{Z_{R}}(u)$ for all $u$ if and only if $Z$ is equal to $Z_{R}$. Accordingly, $M(u)$ forms an appropriate basis for analysing income mobility, when the notion of income mobility is defined as an equalizer of permanent income. Thus, as demonstrated by expression (2.1), low permanent income inequality (high value of $L_{\mathrm{Z}}(u)$ ) can either be due to low short-term inequality (high value of $L_{Z_{R}}(u)$ ) or to high income mobility.

Here our concern is with top income mobility, and we therefore focus on the income shares measured from the top downwards. Following the approach described above, we define the top income mobility (TIM) curve as:

$$
T(u)=\sum_{t=1}^{r} \frac{\mu_{t}}{\mu}\left(1-L_{t}(u)\right)-(1-L(u))=\sum_{t=1}^{r} \frac{\mu_{t}}{\mu}\left(L(u)-L_{t}(u)\right)
$$

where $X_{t}$ with distribution function $F_{t}$, mean $\mu_{t}=E X_{t}$ and Lorenz curve $L_{t}$ denotes the income of an individual in year $t$, and $X=\sum_{t=1}^{r} X_{t}$ is a random variable with distribution $F$, mean $\mu=\sum_{t=1}^{r} \mu_{t}$ and Lorenz curve $L$. Thus, $T(u)$ measures the difference between the observed income share $(1-L(u))$ of the top $100(1-u)$ per cent and their hypothetical maximum share in the case where their positions in the short-term income distributions are assumed to be fixed; i.e. the richest person in period 1 is assigned the highest income in the remaining $s-1$ periods, the second richest person in period 1 is assigned the second highest incomes in the $s-1$ remaining periods, etc. This is illustrated in Figure 3. Note that

$$
L(u) \geq \sum_{t=1}^{r} \frac{\mu_{t}}{\mu} L_{t}(u)
$$

and that equality is attained if and only if there is no mobility, which means that $T(u)=0$ in this case. 


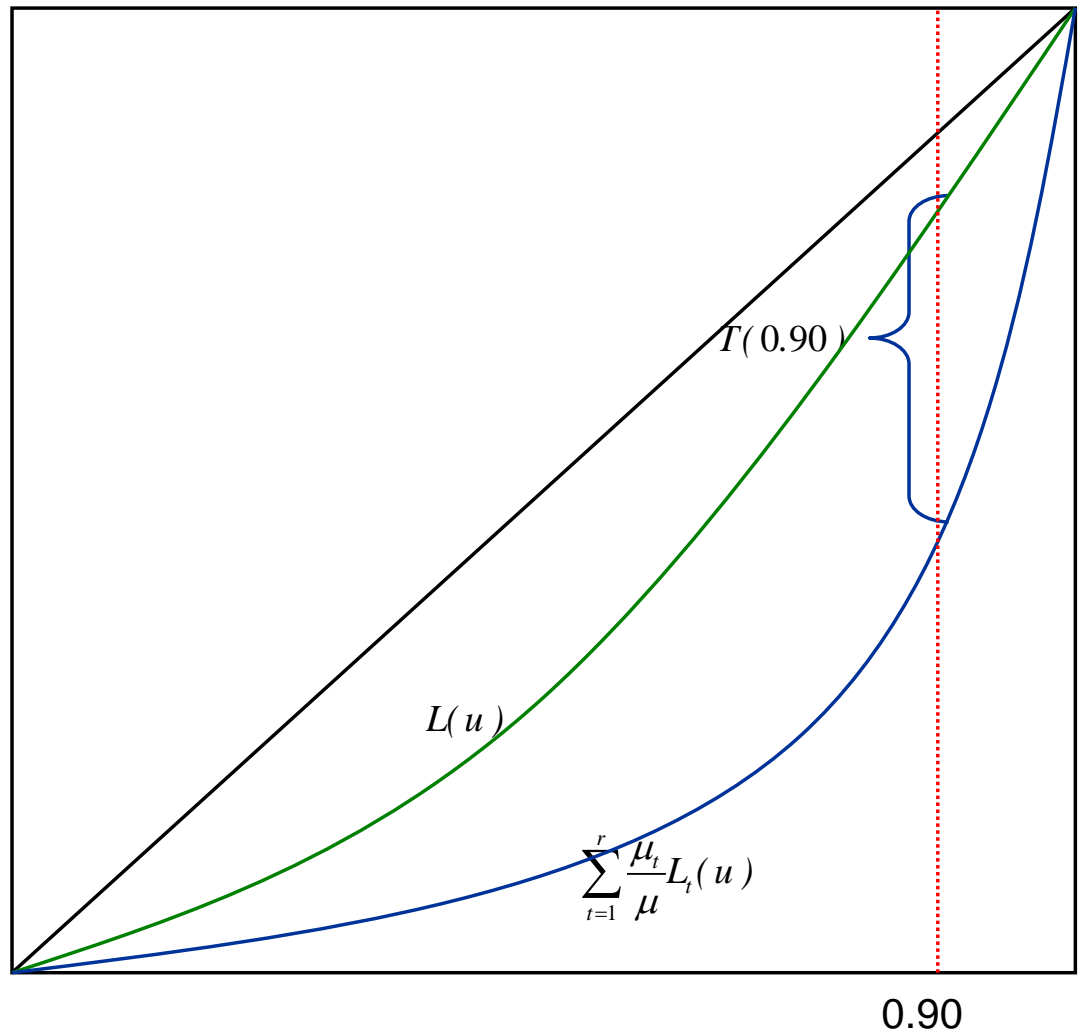

The derivative of the TIM curve provides information of the impact of top income mobility on different parts of the upper tail of the distribution of permanent income. The derivative of $T$ is given by

$$
T^{\prime}(u)=\frac{F^{-1}(u)-\sum_{t=1}^{T} F_{t}^{-1}(u)}{\mu}, u \in[0,1] .
$$

Individuals for which $T^{\prime}(u)$ is positive (negative) become better (worse) off because of income mobility: their incomes are higher (lower) than what they would have been in the absence of changes in relative incomes over time.

\subsection{Partial rankings}

Assume that $T_{1}$ and $T_{2}$ are two TIM curves, where $T_{1}(u) \geq T_{2}(u)$ for all $u \in[0,1]$ and the inequality is strict for at least one value of $u \in\langle 0,1\rangle$. Then we say that $T_{1}$ exhibits more top income mobility than $T_{2}$. It follows directly from the relationship between the TIM curve and the Lorenz curve (see (2.2)) that the higher of two non-intersecting TIM curves can be obtained from the lower 
TIM curve by Pigou-Dalton permanent income transfers ${ }^{3}$, which means that the Pigou-Dalton principle of permanent income transfers provides a normative justification for first-degree TIM dominance. Note that the permanent income version of the Pigou-Dalton principle of transfers requires that that the period-specific income distributions are kept fixed.

In practice, however, TIM curves might intersect, in which case weaker criteria than firstdegree TIM dominance are required. Since TIM mobility is concerned with the degree of mobility among the most affluent people in the society it appears attractive to introduce the criterion of seconddegree downward TIM dominance by integrating the TIM curve from above, which is parallel to the concept of "downwards Lorenz dominance" in Aaberge (2009).

Definition 2.1. A TIM curve $T_{1}$ is said to second-degree downward dominate a TIM curve $T_{2}$ if

$$
\int_{u}^{l} T_{1}(\mathrm{t}) d t \geq \int_{u}^{l} T_{2}(\mathrm{t}) d t \text { for all } u \in[0,1]
$$

and the inequality holds strictly for some $u \in\langle 0,1\rangle$.

Using integration by parts we get the following alternative expression for the downward integrated TIM curve,

$$
\int_{u}^{1} T(s) d s=\sum_{t=1}^{r} \frac{\mu_{t}}{\mu} \int_{u}^{1}\left(1-L_{t}(s)\right) d s-\int_{u}^{1}(1-L(s)) d s=\frac{1}{\mu} \int_{u}^{1}(s-u)\left(\sum_{t=1}^{r} F_{t}^{-1}(s)-F^{-1}(s)\right) d s .
$$

The integrated TIM curve can be considered as a difference between sums of weighted income shares, where the weights increase linearly with increasing rank of the income receiver in the income distribution. So that, if we are considering the top proportion $\mathrm{u}$, a weight of zero is given to those at the cut-off, but a weight of (1-u) to the very top income. Thus, a social decision-maker who prefers the second-degree downward dominating of two intersecting TIM curves pays more attention to inequality reduction the higher up in the permanent income distribution the Pigou-Dalton transfer takes place. Where $u=0$, this corresponds to the following expression in terms of the Gini coefficient of permanent income $(G)$ and the Gini coefficients in different periods $\left(G_{i}\right)$ :

\footnotetext{
${ }^{3}$ The Pigou-Dalton principle of transfers states that an income transfer from a richer to a poorer individual reduces income inequality, provided that their ranks in the income distribution are unchanged.
} 


$$
\sum_{i} \frac{\mu_{i}}{\mu}\left(G_{i}-G\right)
$$

which is the reduction in the Gini inequality due to mobility.

\subsection{Summary measures of top income mobility}

By allowing the proportion $u$ of people classified as "rich" to vary, the TIM curve can be used to study the mobility among affluent people in a society. In cases where downward integrated TIM curves defined by (2.4) intersect, it will be useful to apply summary measures of top income mobility to achieve a complete ranking. Moreover, summary measures offer quantification of the extent of top income mobility of a permanent income distribution. By introducing an appropriate preference relation on the set of TIM curves, an axiomatically justified family of mobility measures can be obtained. To this end we introduce the ordering $\succeq$ defined on the family $\boldsymbol{T}$ of TIM curves. Since the TIM curve $T$ is uniquely determined by two Lorenz curves, we can impose similar conditions on the ordering $\succeq$ as Aaberge (2001) used for an ordering defined on the family of Lorenz curves. That is, the ordering $\succeq$ is assumed to be transitive, continuous, complete and to rank $T_{1} \succeq T_{2}$ if $T_{1}(u) \geq T_{2}(u)$ for all $u \in[0,1]$. More importantly, to give the order relation $\succeq$ an empirical content we introduce the following independence condition

Axiom (Independence). Let $T_{1}, T_{2}$ and $T_{3}$ be members of $\boldsymbol{T}$ and let $\alpha \in[0,1]$. Then $T_{1} \succeq T_{2}$ implies $\alpha T_{1}+(1-\alpha) T_{3} \succeq \alpha T_{2}+(1-\alpha) T_{3}$.

It can be proved that the ordering $\succeq$ which satisfies these axioms can be represented by the following family of top income mobility measures ${ }^{4}$ :

$$
\theta_{q}(a ; T)=-\int_{a}^{1} q(s) d T(s)=\frac{1}{\mu} \int_{a}^{1} q(s)\left(\sum_{t=1}^{r} F_{t}^{-1}(s)-F^{-1}(s)\right) d s,
$$

where $q$ with $q(a)=0$ is a positive non-decreasing weighting function defined on the unit interval and $100(1-a)$ is the proportion of people with higher income than $F^{-1}(a)$. This means that $\theta_{q}(a ; T)$ is

\footnotetext{
${ }^{4}$ These four axioms are analogous to the four axioms underlying the expected utility theory for choice under uncertainty. For a proof of the characterization result we refer to Fishburn (1982).
} 
equal to a weighted average of the differences between the observed permanent income (over $r$ periods) and its no mobility counterpart for the richest $100(1-a)$ proportion of the population.

First-degree mobility dominance requires that $q$ is non-decreasing. The preference function $q$ assigns weights to the permanent incomes of the individuals in accordance with their rank in the distribution of permanent income. As is demonstrated by Theorem 2.1 below the criterion of second-degree downward TIM curve dominance justifies the condition of convex weighting functions.

Theorem 2.1. Let $T_{1}$ and $T_{2}$ be members of $\boldsymbol{T}$. Then the following statements are equivalent, (i) $\quad T_{1}$ second-degree downward dominates $T_{2}$

(ii) $\quad \theta_{q}\left(a ; T_{1}\right)>\theta_{q}\left(a ; T_{2}\right)$ for all positive non-decreasing convex $q$ where $q^{\prime}(a)=q(a)=0$.

\section{Proof in the Appendix.}

In order to arrive at a specific measure, it is necessary to choose the weighting function, $q(s)$, and to specify the range over which we are considering mobility (i.e. the value of $s$ ). Here we consider the following family of non-decreasing weighting functions $q_{k}$ where $q_{k}^{\prime}(a)=q_{k}(a)=0$,

$$
q_{k}(s)=\frac{k}{(1-a)}\left(\frac{s-a}{1-a}\right)^{k-1}, a \leq s \leq 1, k=1,2, \ldots
$$

Note that $q_{k}$ is convex for $k>1$, which means that the top income mobility measure defined by $k=1$ does not satisfy second-degree downward dominance. Inserting (2.6) into (2.5) yields the following family of top income mobility measures ${ }^{5}$,

$$
\tilde{\theta}_{k}(a ; T)=\frac{k}{(1-a)^{k} \mu} \int_{a}^{1}(s-a)^{k-1}\left(\sum_{t=1}^{r} F_{t}^{-1}(s)-F^{-1}(s)\right) d s, k=1,2, \ldots .
$$

Referring back to (2.4), we can see that $k=2$ is the case of integration under the TIM curve. When $k=1$

\footnotetext{
${ }^{5}$ Note that this family of top income mobility measures is associated with a family of rank-dependent measures of "affluence" (for $a=0.5$ ) introduced by Aaberge and Atkinson (2013).
} 


$$
\tilde{\theta}_{1}(a ; T)=\frac{\sum_{t=1}^{r} E\left(X_{t} \mid X_{t} \geq F_{t}^{-1}(a)\right)-E\left(X \mid X \geq F^{-1}(a)\right)}{\mu} .
$$

When $k=2$

$$
\tilde{\theta}_{2}(a ; T)=\tilde{\theta}_{1}(a ; T)+\frac{1}{\mu}\left(\sum_{t=1}^{r} G^{*}\left(a ; F_{t}\right)-G^{*}(a, F)\right)
$$

where $G^{*}(a ; F)$ and $G^{*}\left(a ; F_{t}\right)$ denote the absolute Gini coefficients of the conditional distributions of $X$ given $X \geq F^{-1}(a)$ and $X_{t}$ given $X_{t} \geq F_{t}^{-1}(a)$, which means that the second term of $\tilde{\theta}_{2}$ is a measure of the difference in spread between the upper tails of the cross-sectional and permanent income distributions. An interesting question is whether $\tilde{\theta}_{k}$ for $k>2$ has a similar relation to summary measures of inequality as $\tilde{\theta}_{2}$ to the upper tail Gini coefficient. By noting that the upper tail version of the (absolute) Lorenz family of inequality measures (Aaberge, 2000) can be expressed as follows

$$
D_{k}^{*}(a ; F)=\frac{k}{(k-1)(1-a)^{k}} \int_{a}^{1}(s-a)^{k-1} F^{-1}(t) d t-\frac{\mu^{*}(a)}{k-1}, k \geq 2
$$

where $\mu^{*}(a)=E\left(X \mid X \geq F^{-1}(a)\right)$ we get the following alternative expression for $\tilde{\theta}_{k}$ by inserting (2.10) into (2.7),

$$
\tilde{\theta}_{k}(a ; T)=\tilde{\theta}_{1}(a ; T)+\frac{k-1}{\mu}\left(\sum_{t=1}^{r} D_{k}^{*}\left(a ; F_{t}\right)-D_{k}^{*}(a ; F)\right), k \geq 2 .
$$

Note that $D_{2}^{*}(a ; F)=G^{*}(a ; F)$ and that $D_{k}^{*}(a ; F)$ increases its sensitivity to changes among the most affluent people with increasing $k$. This means that $D_{3}^{*}(a ; F)$ is more sensitive to changes in the dispersion of incomes among the most affluent people than $G^{*}(a ; F)$. The most affluence-sensitive $\tilde{\theta}_{k}$-measure is obtained as $k$ approaches $\infty$. In this case the top income mobility measure is defined by

$$
\tilde{\theta}_{\infty}(a ; T)=\frac{\sum_{t=1}^{r} F_{t}^{-1}(1)-F^{-1}(1)}{\mu},
$$

where $F_{t}^{-1}(1)$ is the highest income in period $t$ and $F^{-1}(1)$ is the highest long-term (permanent) income. 


\section{Top income mobility in Norway 1967-2011}

There have been several studies of intra-generational top income mobility. Reference was made earlier to the results of Auten et al (2013) for the United States. Saez and Veall (2007) study mobility in Canada by comparing top $0.1 \%$ income shares for accounting periods of one, three, and five years, and argue that mobility has been roughly constant since 1982, although they do not compare this to any reference distribution. Kopczuk et al (2010) examine the top $1 \%$ in the US from 1978 onwards, and find that an increase in the accounting period from one to five years does not substantially alter the top earnings share.

There have been studies of inter-generational mobility, notably that of Björklund, Roine and Waldenström (2012) for fathers and sons in Sweden. Here we present evidence on intra-generational mobility for Norway since 1967. This serves both to illustrate the application of the methods developed in the previous section and to throw light on a country and a period that is of considerable interest. Norway is a relatively egalitarian country but one that saw a large rise in top income shares as shown in Figure 1.

The data used are the same as those for calculating top income shares since 1967, with two exceptions. We limit our analysis to individuals with permanent residence in Norway, and we use as control total the total income from the tax registry rather than a fixed share of the disposable income post of the National Accounts. As is common in the literature (see Atkinson and Piketty, 2007, 2010), we will focus on the shares of the $10 \%, 5 \%, 1 \%, 0.5 \%$ and $0.1 \%$ richest. Initially the number of periods used to calculate permanent income, $r$, is set at 3 . A higher number of periods would by definition give higher mobility. On the other hand, this would extend our "moving average" giving both shorter time series overall and less insight into short-term variations in mobility. However, we return to the implications of alternative choices of $r$ in Section 3.4 below. To simplify the discussion, the three-year periods will be denoted by the end year. In calculating permanent income, incomes are adjusted using the Consumer Price Index.

\subsection{The level of top income mobility}

Figure 4 shows the overall evolution of three-year top income shares since 1967. The highest line is the average of the top income shares over the last three years. The lowest line is the income shares of those with the highest average incomes over the same years. The figures are displayed for $\mathrm{u}=0.9,0.95,0.99,0.995$ and 0.999 , and top income mobility, $T(u)$, is given by the difference between the two graphs in Figure 4. The first overwhelming impression is that the difference is small: there is little mobility. For the period 1998-2000, for example, the top 1 per cent share of permanent income 
was 9.17 per cent, whereas the average top 1 per cent share in the previous three years was 9.71 per cent. For the top 0.1 per cent, the corresponding figures were 3.34 per cent and 3.79 per cent.

Figure 4. Cross-sectional and permanent top income shares (three-year averages). 1967-2011

\section{Top income shares}

Top $10 \%$

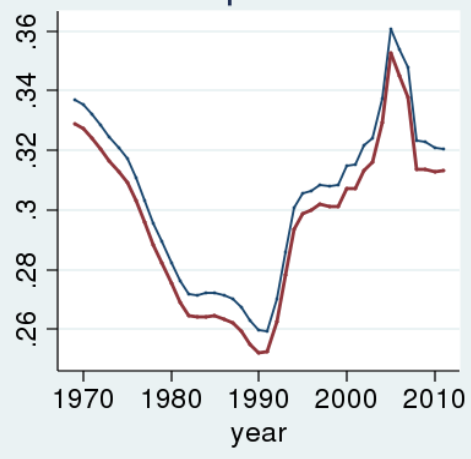

Top $0.5 \%$

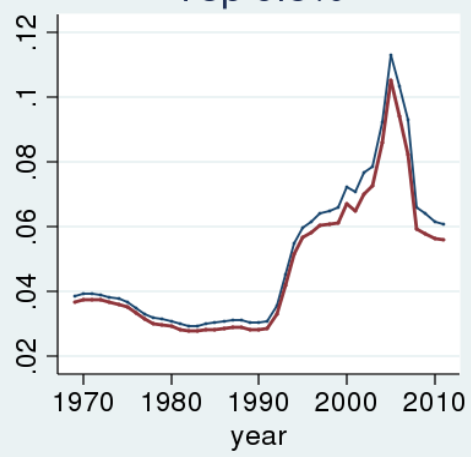

Top 5\%

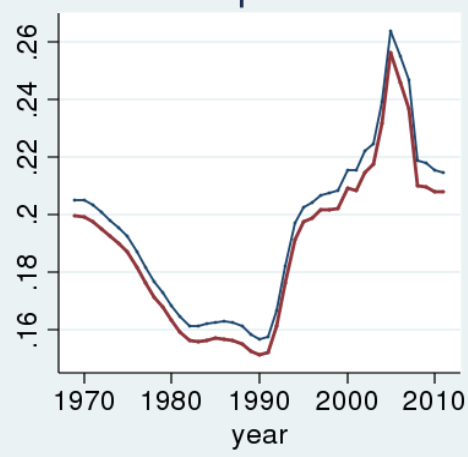

Top $0.1 \%$

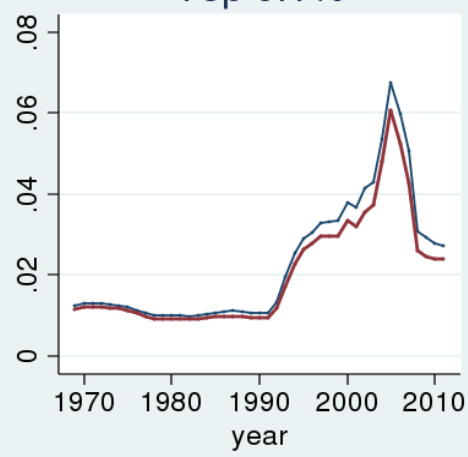

Top $1 \%$

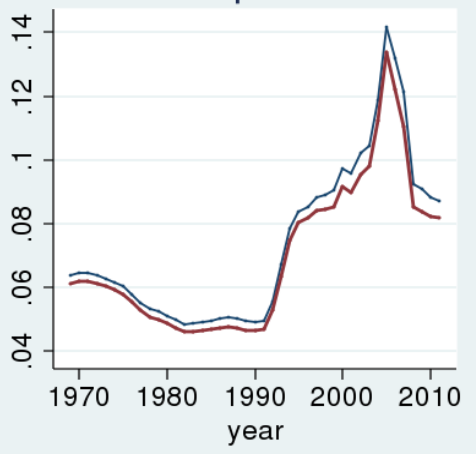

year

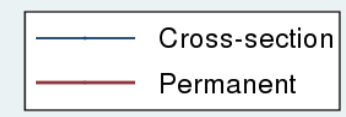

The extent of top income mobility, defined as the difference (in percentage points) between these two income shares, is shown in Figure 5. With the exception of the 2005 spike, discussed separately in Section 5, the differences are all less than 1 percentage point. For the first part of the 2000s, they are indeed clustered between 0.4 and 0.9 percentage points for the top income groups shown. For nearly all periods, $T(u)$ is decreasing in $u$. For example, in the first period, 1967-1969, $T(0.9)=0.79$ percentage points while $T(0.95)=0.55$ percentage points. As $T$ is an absolute measure, this is not unexpected. The differences between the hypothetical 3-year distribution (the connection of the marginal income distributions by rank) and the associated observed distribution are larger when more people move in and out of the group in question over the years. If we consider an income distribution profile for a given year and look at the richer end, there are typically two characteristics of such a distribution. First, the average absolute distance between individuals' incomes increases. Second, the average absolute income volatility increases. In the data, we see that the first effect is stronger than the 
second. Hence, the number of crossing income paths decrease as we move the threshold u towards the top end of the income distribution. We are measuring mobility here in absolute terms - since this provides a better guide to the degree of mobility across different time periods and different countries when the income shares are quite different.

Figure 5. Top income mobility, selected quantiles, 1967-2011

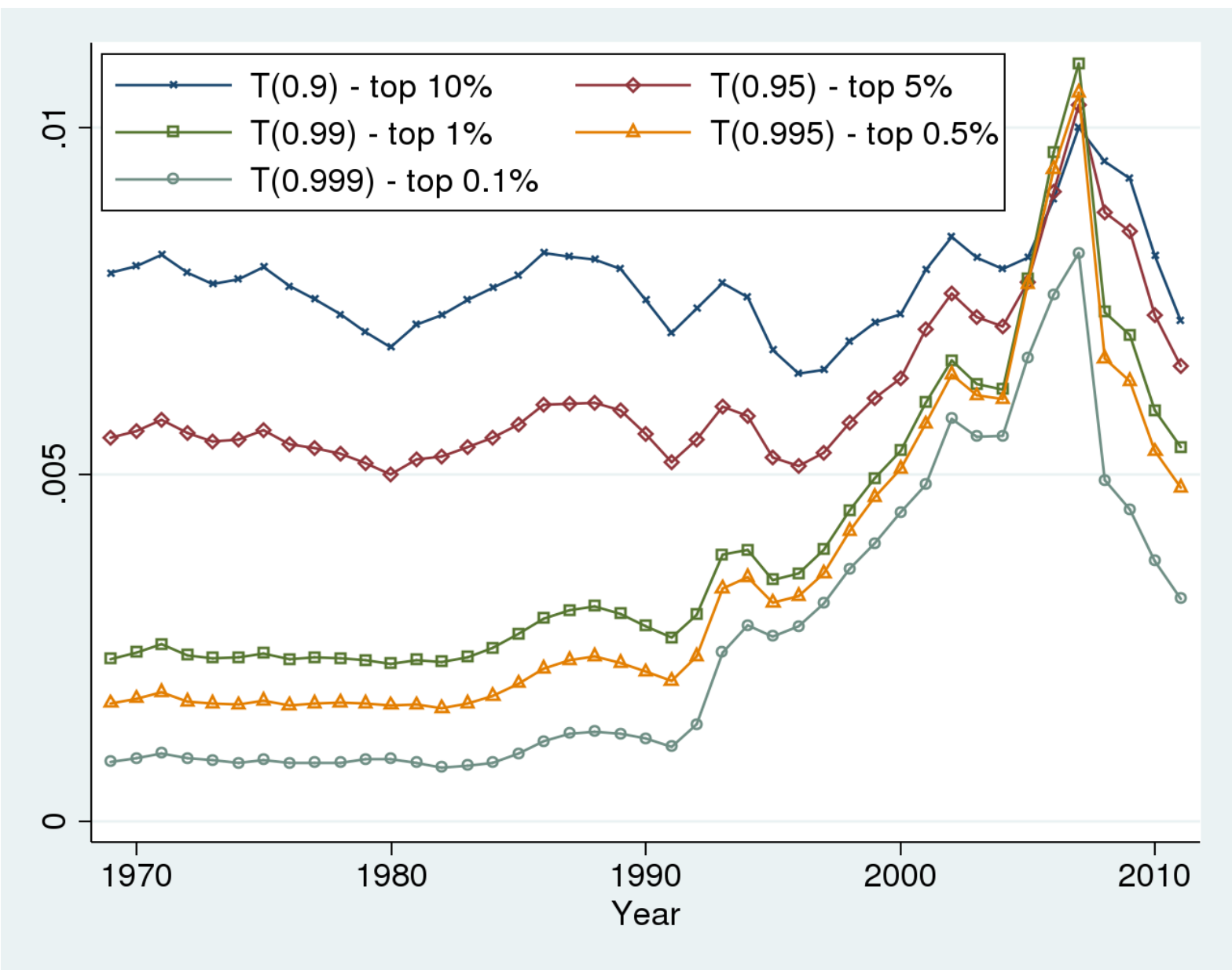

\subsection{The trend over time in top income mobility}

From Figure 5, we can see, for all five levels of $\mathrm{u}$, a nearly trendless development in mobility from 1969 to 1992, followed by a period of rapid growth. In the period with falling top income shares, mobility was stable. From 1991, there is a steady increase in top income shares as well as in mobility. The change in mobility is gradual, going over several years, and is interrupted by decreases in 1995 and 2003. We see the highest effects at the top; $T(0.995)$, for example, increases from a pre-1990 level of 0.2 percentage points to more than one percentage point for the 2005-2007 period - an increase by more than a factor of five. $T(0.9)$, on the other hand, only increases by about $20 \%$. In the mid-2000s, 
there is the spike discussed in Section 5. After 2007, mobility recedes to previous levels. Our data ends in 2011, when mobility was back at the levels of 1998 (for $T(0.999)$ ) to 2000 (for $T(0.9)$ ).

The level of top income mobility given in Figure 5 is for selected points on the top income mobility curve. We can draw this curve for all values of $u$, as shown in Figure 6 for five selected years. The intersection of the lines to the right of the figure corresponds to the crossing of the time trends in Figure 5. We also see the impact of increased labour force participation (mainly among women) since the 1960s; while $30 \%$ of the population had no income over a three-year period,and hence no mobility, in 1967-1969, this portion had shrunk to less than $5 \%$ by the 1980 s.

Figure 6. Top income mobility curve $T$ of the entire distribution for selected three-year windows

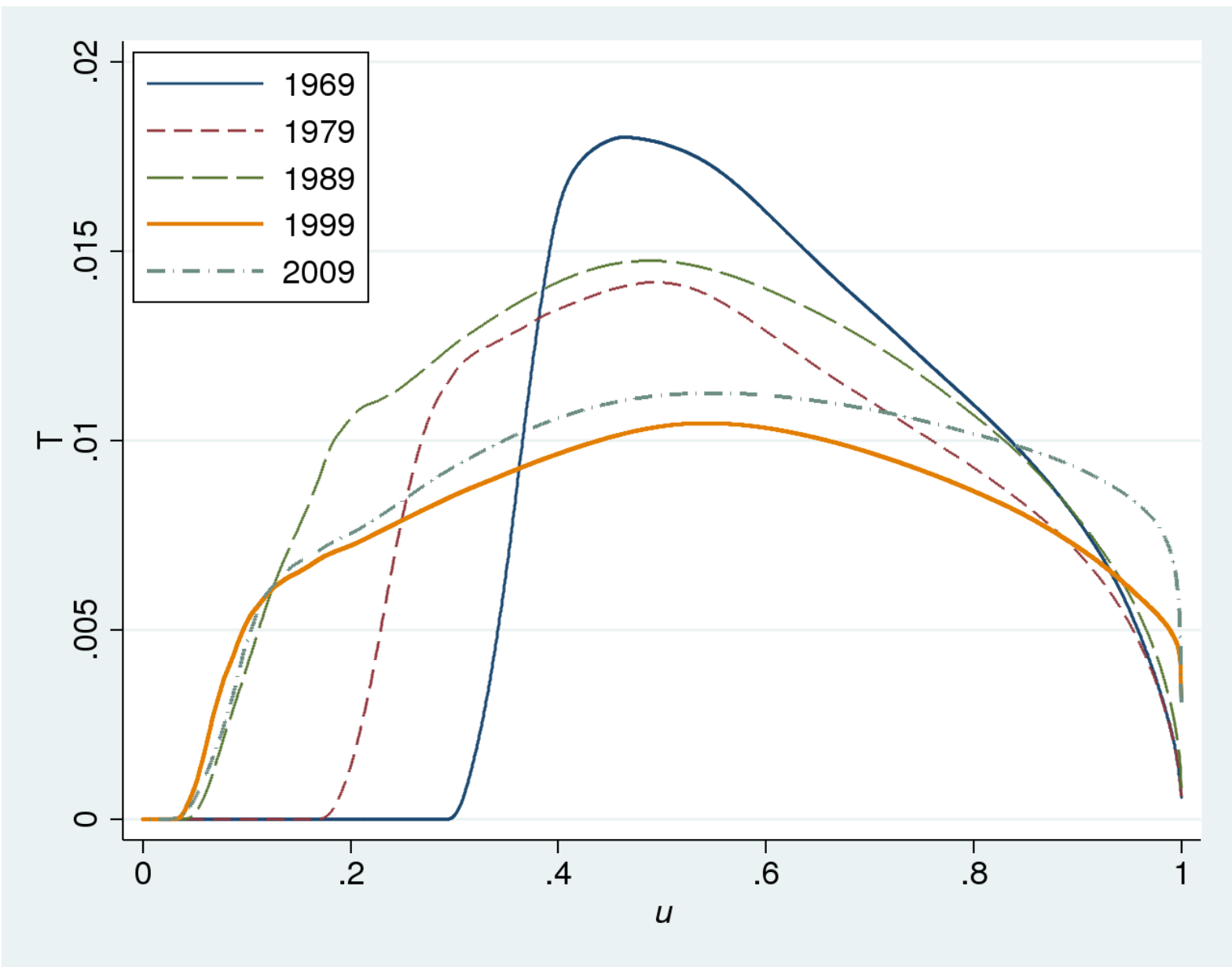

As stated in Section 2, while the level of the top income mobility curve reflects the degree of top income mobility, the slope represents the individual loss (or gain) from income mobility. For 1969-1989, the curve is relatively steep downward sloping for the richest percentiles (high $u$ ), implying an individual at a high percentile in the three-year permanent income distribution would experience a high income growth if moving to the same percentile in a hypothetical stationary cross- 
section distribution for the same three years. However, except for the very richest, the curves for 1999 and 2009 are much flatter. We examine the time trend in $T^{\prime}(u)$ in more detail in Figure 7.

Figure 7. Derivatives of top income mobility curves based on three-year windows. 1969-2011
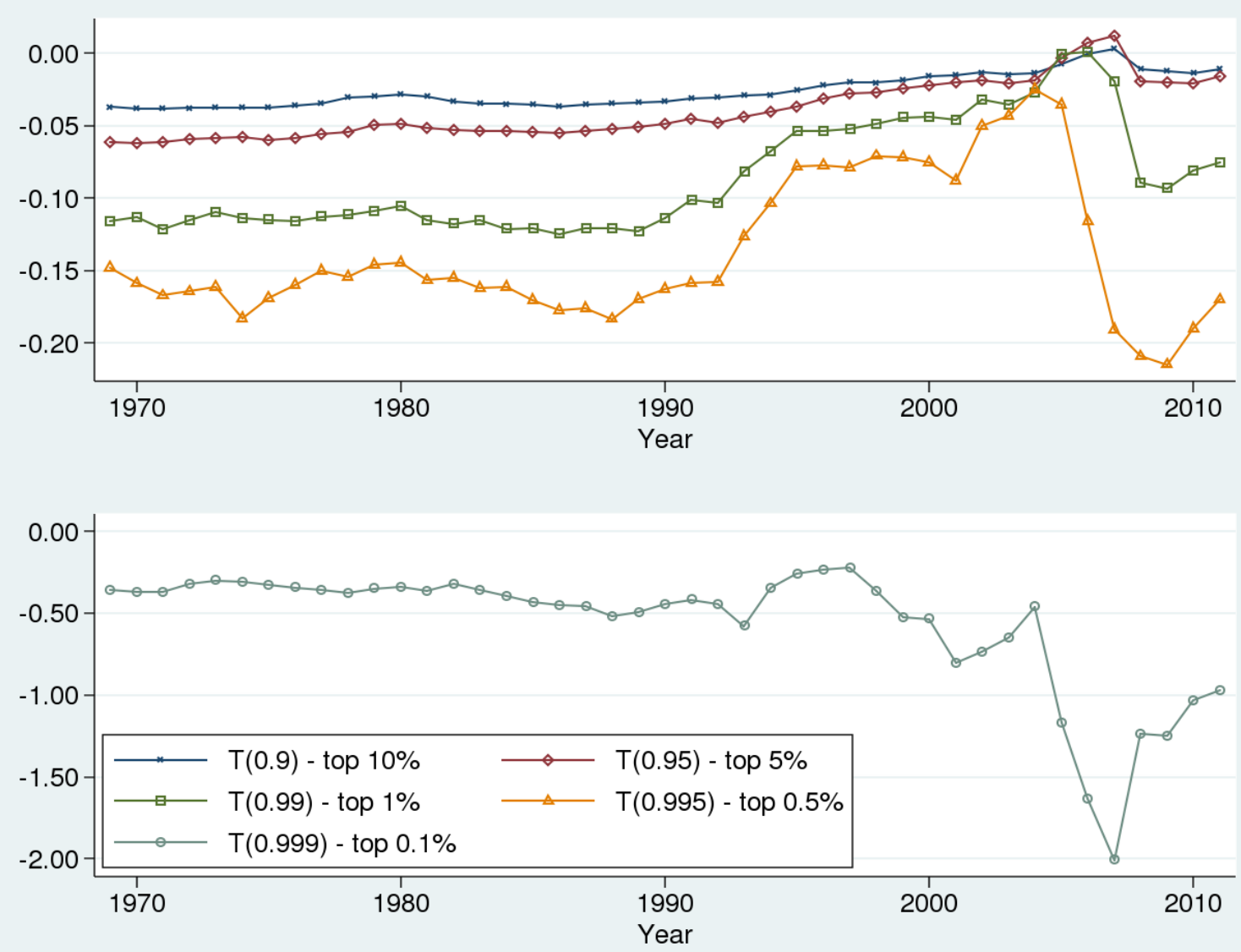

Figure 7 shows the stable time trend in losses from income mobility among the rich over time for five points near the top of the income distribution. As shown in Figure 6, both the level and slope of the top income mobility curve did not change much in the first part of the period, from 1969 to the early 1990s. For example, in 1969, the slope of $T$ at $u=0.90$ was minus 3.7 per cent - the "loss" for the individual at the 90th percentile divided by the mean income of the entire population. For the 99.5th percentile this loss was 14.8 per cent of the overall mean income. The higher share for the very richest reflects both the higher average incomes and the comparatively larger movements in and out of this very small group. From 1993 onward, the TIM curve becomes much less steep, as shown by higher values of $T^{\prime}(u)$, in particular for the top 1 and 0.5 per cent. Contrasting these features with the increasing T(u) curves shown in Figure 5, we get a broader picture of how mobility changed. While $T(u)$ summarizes changes in the difference of income shares above $\mathrm{u}, T^{\prime}(u)$ is equal to the difference between hypothetical and actual mean income for an individual at the $u$-quantile. Figure 7 shows that 
increasing mobility in the 1990 s mainly took place at the very top $(\mathrm{u}=0.999)$, while the changes in the last decade affected the top 1 per cent. At $\mathrm{u}=0.999$, the slope of the $T$ curve is very steep; $T^{\prime}(u)$ is nearly always twice as high as for $u=0.95$. For this reason, the development over time is shown separately in the lower panel of Figure 7. There is a slight decrease in the slope from 1969 to 1993. After this, the fall is similar to that observed in the upper panel. However, the subsequent decrease, first to the through of 2001 and then to that in 2007, gives extremely low values. For 2005-2007 ( $t=2007$ in the figure) the loss from mobility for the individual at the 999th per mille was twice the average income in the population. This reflects the large replacement of the very richest after the tax reform, as mentioned above. While "twice the average income" seems like a very high income, we should remember that the average income of the 1 per mille richest is much higher than that - in 2005 , this group had on average more than fifty times the income of the average individual. These results show that most of the changes in mobility in the 2000s took place at the very top ( $1 \%$ and above), and that this also drives a substantial part of the changes in top income mobility at the top 5\% and top $10 \%$.

\subsection{Dominance results}

This section examines whether it is possible to achieve a complete ranking of top income mobility when we compare the various three-year periods. First, we can examine first- and secondorder dominance, as defined in Section 2.2. By the first-degree dominance criteria of Definition 2.1, we find unambiguously increasing mobility in the early 1980 s. $^{6} 1980$ is dominated by the next nine top income mobility curves; 1981 by six out of seven, and 1982 by five out of six. The next unambiguous change is the decreasing mobility of the early 2000s, where 2002 dominates 2003 and 2004. Then, the increasing in the mid-2000s is shown by 2005 and 2006 both dominating 2007.

When we introduce the weaker second-degree downward dominance criterion, we also find increasing mobility from 1970 to 1971, and several episodes of decreasing mobility in the early 1970s and late 1980s. The increase of the late 1990s is very robust, with for example 1997 dominating all subsequent years. The decrease from 2008 to 2009 is also unambiguous. However, there are still some periods where there is not second-degree dominance, such as when comparing the very early with very

\footnotetext{
${ }^{6}$ Because there is a lot of volatility in T at the very top, Definitions 2.1 and 2.2 are applied only in the interval $[0,0.99]$. The integrands in 2.2 are however summed all the way up to 1 . This implies that in some cases, first-degree dominance can be stricter than second-degree dominance. This is indeed the case in a small set of year comparisons, but does not affect the results to any substantial degree. Detailed tabulations of all year comparisons are available on request.
} 
late periods. We therefore turn to the summary measures $\tilde{\theta}_{k}(a ; T)$, defined in Section 2.3. For this purpose, we have to decide on the field over which mobility is being measured: i.e. the value of $a$.

Figure 8. Summary measures of top income mobility, based on three-year windows
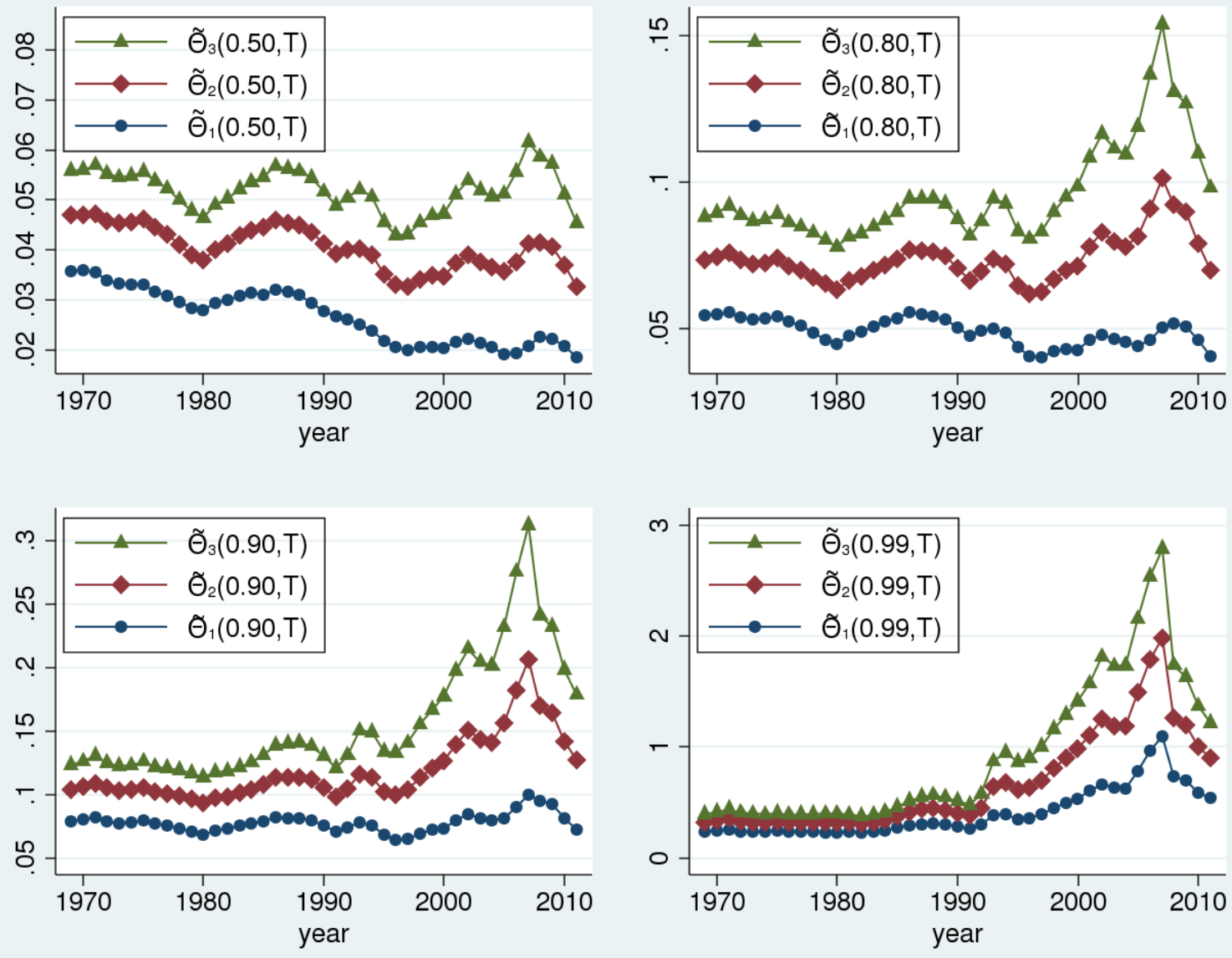

Figure 8 shows the development over time of this summary measure for three values of $\mathrm{k}$ and four values of a. When we are concerned with the top 50 per cent $\left(\left(\tilde{\theta}_{2}(0.5 ; T), \mathrm{k}=1,2,3\right)\right.$ upper left panel $)$ mobility in 2011 is always lower than in 1969, though the extent of the decrease varies with the weight $k$ given to the upper incomes. When mobility is measured by the difference in mean incomes above the median $\left(\tilde{\theta}_{1}(0.5 ; T)\right)$ we find a relatively smooth decrease in mobility over time, whereas $\tilde{\theta}_{2}(0.5 ; T)$ and $\tilde{\theta}_{3}(0.5 ; T)$ shows more variation. In particular, the increase from the late 1990s and the effect of the tax reform are more pronounced for $\tilde{\theta}_{3}$. For $\mathrm{a}=0.80$, shown in the upper right panel, the graphs look more similar to the mobility indices reported in Figure 5, in particular if we put more weight at the very top $\left(\tilde{\theta}_{3}(0.8 ; T)\right)$. By further increasing $a$, we find that the variation before 1995 decreases in 
importance and the 2000s becomes even more pronounced. As shown by Figure 6, significant changes in the pattern of mobility took place further down in the income distribution in the late 60 s and early 70 s, which was mainly due to the increasing female participation in the labour market. This pattern is also captured by the summary measures for $u=0.50$ and partly $u=0.80$, but the effects are much lower at the upper end of the income distribution.

\subsection{The sensitivity to time horizon}

So far, we have looked at top income mobility over a 3-year horizon. However, it is also of interest how large the top income mobility is over longer horizons. The disadvantage of a longer horizon is that short-term fluctuations become less visible as we average over longer periods of time. 
Figure 9. Top income mobility based on 2- to 15-year averages centered at 1985 (for odd numbers) and 1985-1986 (for even numbers)
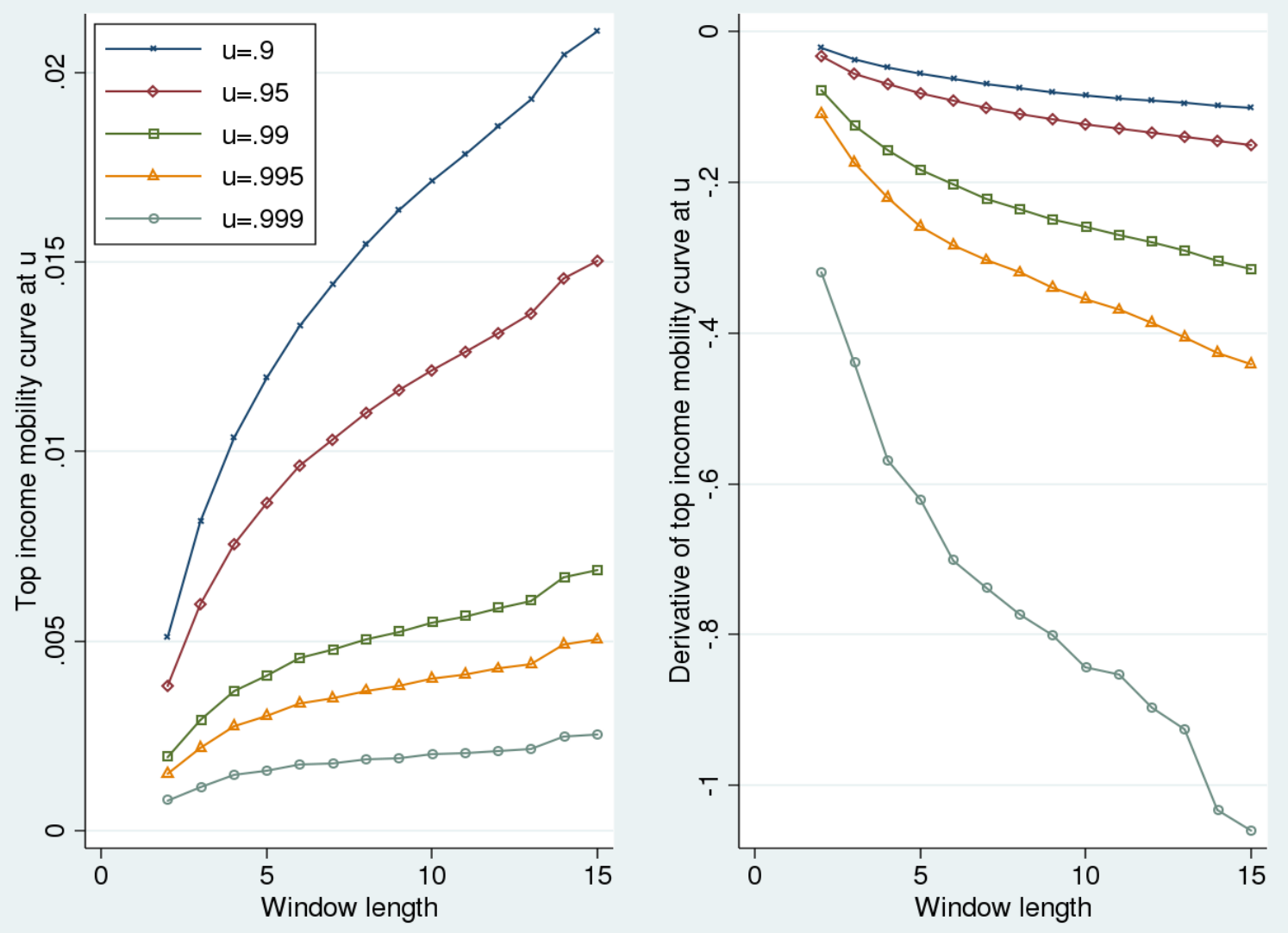

Windows centered on 1985

The left panel of Figure 9 shows values for T(u) when we use different window lengths, from 2 to 15 years - with a length of 1, mobility would by definition be zero. The windows are centred on 1985 (or 1985.5 in case of even-numbered horizon lengths). Mechanically, when we increase the horizon, mobility goes up. We compare the cross-section and permanent income top income shares over more years, including more years of crossing income paths. We also include a longer time period, so the comparison is not straightforward - for the 15-year window, the endpoint is in 1992, a slightly more volatile period. The increase in mobility is most visible for the top 10\%, where we se an increase from 0.5 percentage points to 2.1 percentage points. For the top $0.1 \%$, the increase is from 0.07 percentage points to 0.25 percentage points, which means that top income earners roughly speaking maintain their positions in the cross-sectional income distributions over time.

The right panel of Figure 9 shows how the loss of income mobility $\mathrm{T}^{\prime}(\mathrm{u})$ changes with window length. Here it is also the case that the effects become stronger with longer windows - the loss grows as $r$ moves from 2 to 15 . Here the effects are strongest at the top, with $\mathrm{T}^{\prime}(0.999)$ - the loss for the top $0.1 \%$ 
- varying from 32 to 106 per cent of the overall mean income. The latter case means that the top 0.1 per cent income share over 15 years would have increased from 0.76 per cent to 1.01 per cent if there were no mobility.

Plots of the entire time series with longer window length (available on request) shows no difference from the trend with three-year windows shown in Figure 5 above. However, by averaging over more years, the short-term variations in mobility, such as the peak in 2005-2007, do not stand out as much.

\section{Top income mobility over the life-cycle}

Can the change in mobility after 1990 be caused by a demographic bulge? Norway had a low birth rate from 1930-1945 followed by a high birth rate after 1945, as had many other Western countries. Perhaps the reaching of "mature age" by the late-1940s cohorts was responsible for the increase in top income shares and mobility? To study this question, we split the sample into different cohorts, and study them separately. Figure 10 contains $\mathrm{T}(0.95)$ levels based on rolling three-year windows within separate cohorts; for ease of presentation, only every tenth cohort is shown. 
Figure 10: Top income mobility of the 5 per cent richest in selected cohorts

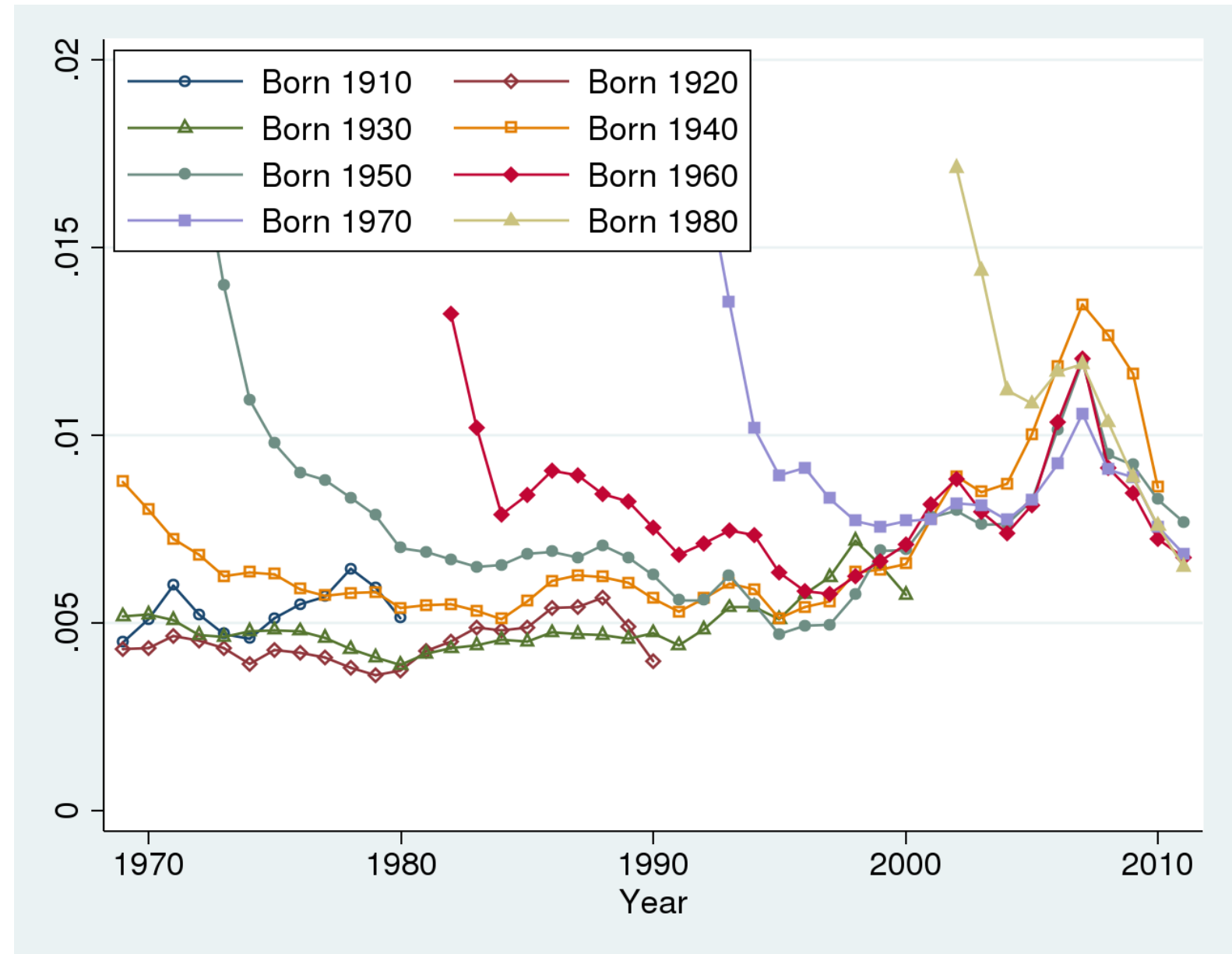

From the figure, it is evident that the increase after 1990 takes place among all cohorts, as does the decrease after 2005. In addition, we observe that the level of $\mathrm{T}(0.95)$ within cohorts is not very different from $\mathrm{T}(0.95)$ for the entire population. We do, however, see a clearly pronounced lifecycle effect. The curves start when individuals are 20 (covering incomes from 18, 19 and 20 years of age) and in these early years mobility is very high. In the first years, the low-educated have much higher income than those still in school; as the higher-educated enter the labour force there is a lot of re-shuffling of the income distribution. Interestingly, we do not see this for the people at the very top (for example the top $0.1 \%$; see appendix figure), suggesting that at the very top, incomes are to a larger extent inherited rather than earned. The life-cycle profiles also show a small "hump" around the ages 60-70. Individuals retire (with associated income loss) at this age, but at different times, leading to changes in the ranking of individuals by income. At age 70 (the curves end at 70-72), this effect has passed as pension incomes are relatively stable. Besides these start and end effects, the main drivers described in the previous section appears to dominate. 


\section{Mobility and the 2005 tax reform}

A striking feature of the behaviour of top shares in Figure 1 is the spike in 2005. This spike is first and foremost due to the implementation of a tax reform in 2006, where taxes on dividends increased from 0 to 28 per cent. $^{7}$ Thus, the rise in top shares in 2005 , and the subsequent fall in top income shares from 2005 to 2006, is largely due to a change in the income reporting behaviour. This filters into the mobility numbers, which have a large peak in 2005-2007.

By examining transition matrices in more detail, we find that there was a replacement of the top income groups between the tax years 2005 and 2006, in particular at the very top. For any given year, 40 to 60 per cent of the population of the top per mille is likely to be found in the top per mille in the following year. However, for 2005-2006, this number is as low as 19 per cent. As Figure 5 shows top mobility, calculated with rolling three-year windows affects both the 2006 and 2007 calculations. A large part of the previous top income earners permanently adjusted their income through legal means such as for owner-managers of closely held firms to increase dividends in 2005 (the tax on dividends was to be increased in 2006 from 0 to 28 per cent), and the low permanence of the top income population suggests that this adjustment persisted after 2006.

\footnotetext{
${ }^{7}$ For a discussion of this reform, see Alstadsæter and Fjærli (2009).
} 
Figure 11: Proportion of individuals by largest income component for the top 0.1 per cent and the entire population, 1993-2011
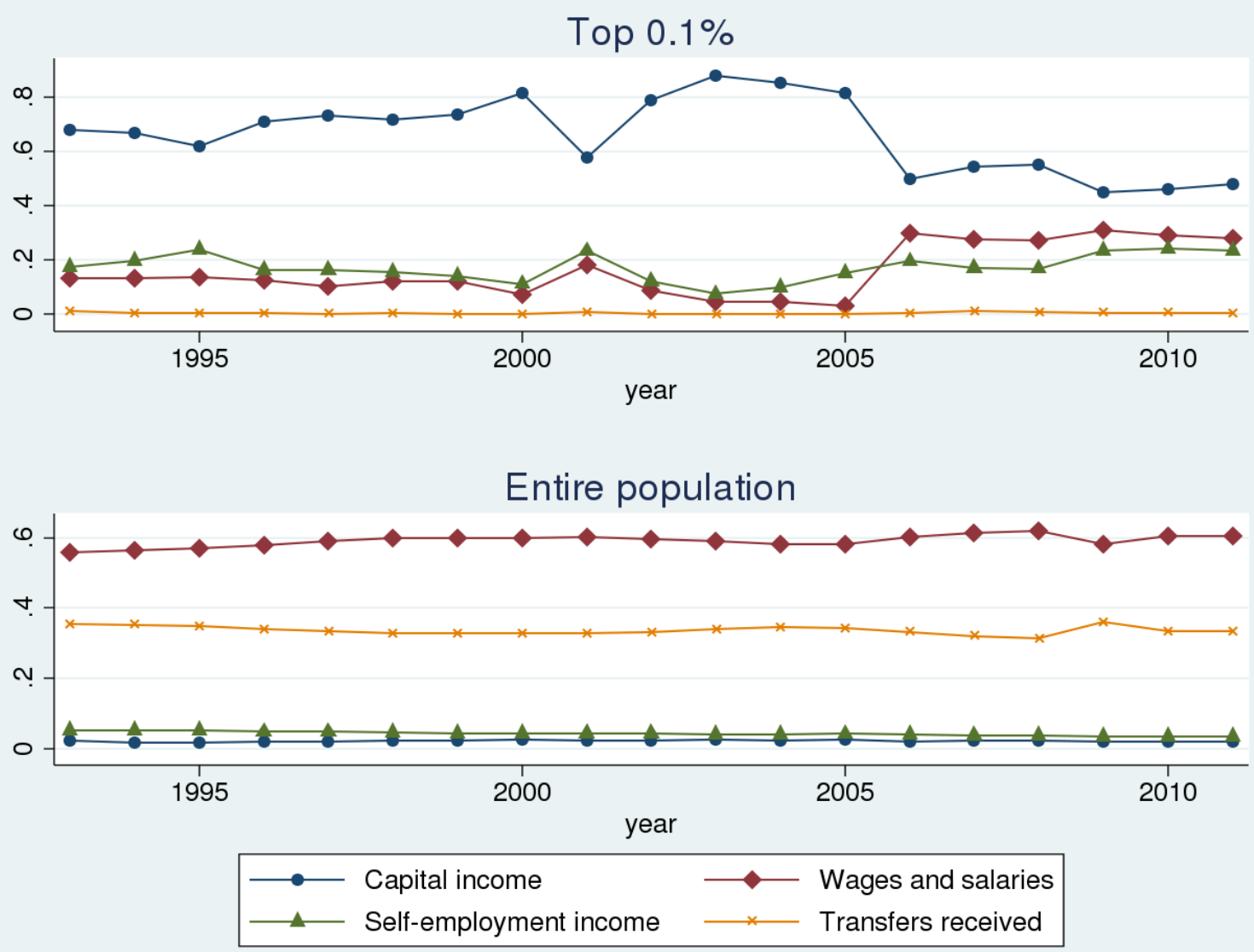

From 1993 onwards, we can make use of more detailed data on income composition from the tax records. Income is decomposed into wages and salaries, net self-employment income, net capital income and net transfers. We then classify individuals according to which type of income constituted the largest share of total income in any given year, and then show the population by largest income component in the lower panel of Figure 11. It is evident that there is not much change over time: around 60 per cent of the population get their main income from wages and salaries, around $35 \%$ from transfers (the majority of these are retirees receiving public pensions), while less than six percent have self-employment income as the most important source and less than three per cent have capital income.

We then turn to the income composition of the richest 0.1 per cent. Until 2005, between 60 and 80 per cent of this group has their main income from capital, while an additional twenty per cent have their main income from self-employment. There is a one-year change with the tax reform in 
2001, where the "usual" top income holders choose not to realize capital income as a tax adjustment. However, 2002 looks similar to 2000.

The reform of 2005, however, changes the composition of top income earners permanently. Many capital-income earners disappear from the top 0.1 per cent - in 2005, 81 per cent of the top 0.1 per cent derived their largest income component from capital, down to 50 per cent in 2006 and a maximum for the post-reform period of 55 per cent in 2008. Self-employment income is largely unaffected, while wages and salaries increase.

In the years before 2005 , around $40 \%$ of the top $0.1 \%$ in any given year was also there the year before. In 2006, however, this number is down to 19\%, and the previous top income holders do not return in the subsequent years. Around nine per cent of the top $0.1 \%$ in 2005 report incomes in the bottom decile in 2006; among the rest, most are found from the eighth decile upwards. The "new" recruits into the very top from 2006 onward mainly come from the top $10 \%$, showing that the high mobility in this year is caused by an exit of a group of capital income earners rather than a radical upward mobility of some particular group.

\section{Conclusions}

This paper has sought to make two contributions to the study of top income mobility. The first is to provide a theoretical framework, introducing the "top income mobility curve" and a family of associated summary measures for comparing income distributions with regard to the extent of income mobility, when mobility is defined to accommodate the notion of income mobility as an equalizer of permanent income. The second is to provide empirical evidence about the extent of mobility, and changes over time, in Norway from 1967 to 2010. We have identified two major changes in top income mobility. First, there was a steady increase in top income mobility from the early 1990s and onwards. For the top 0.1 per cent, mobility increased from 0.11 percentage points in 1991 to 0.58 percentage points in 2002. This can be explained by the general increase in top incomes in this period mainly due to the liberalization of the capital market. Second, there was a large spike in top income mobility in 2005, in anticipation of the 2006 tax reform. For the top 1 per cent top income earners mobility increased from 0.6 percentage points in 2004 to 1.1 percentage points in 2007, and returned to the 2004-level in 2011. Still, we found a permanent change in the identity of the top income earners after the reform. In the years leading up to the change in tax reporting incentives, capital income was the largest income component for 80 per cent of the top 0.1 per cent. After the reform, approximately 50 per cent of the top 0.1 per cent had capital income as their most important component. 
Within-cohort top income mobility at the top 5 per cent shows to be very high at young age, when individuals enter the labor market, but decreases steeply until around age 25 and then slowly until age 45. This within-cohort pattern is remarkably stable over time, though the aggregate trends in top income mobility emerge for each of the cohorts. For the very highest income shares, there is no clear within-cohort pattern. This likely reflects different across-generation transmission methods; education and self-made successes among the moderately well-off such as the top 5 per cent and inheritance among the top 0.1 per cent.

The estimated summary measures of top income mobility show that the development of overall top income mobility varies with the chosen weight assigned to the most affluent people. While short-term fluctuations are similar across all three choices of weights, there is a decreasing trend for $k=1$ (low weight on the right tail) and an increasing trend for $k=3$ (high weight on the right tail). This shows that increases in top income mobility have been larger among those with very high incomes.

Even though there were large changes in top income mobility over the last four decades, the magnitude of the effect of the changes in mobility on the income shares was moderate. When income is averaged over three years, the difference between permanent and cross-section income of the top 10 per cent only reached one percentage point once during the 42-year period. Increasing the number of years over which incomes are averaged does, as expected, increase the level of mobility. Changes over time, however, are robust also to the choice of accounting period. 


\section{References}

Aaberge, R. (2000): "Characterizations of Lorenz curves and income distributions", Social Choice and Welfare 17, 639-653.

Aaberge, R. (2001): “Axiomatic Characterization of the Gini coefficient and Lorenz Curve Orderings", Journal of Economic Theory, 101, 115-132.

Aaberge, R. (2009): "Ranking Intersecting Lorenz Curves", Social Choice and Welfare, 33, 235 - 259.

Aaberge, R. and A. B. Atkinson (2010): “Top Incomes in Norway”. In: Atkinson and Piketty (eds):

Top Incomes - A Global Perspective. Oxford University Press, Oxford.

Aaberge, R. and A. B. Atkinson (2013): “The Median as Watershed”, Discussion Paper No. 749, Statistics Norway.

Aaberge, R. and M. Mogstad (2013): "Income Mobility as an Equalizer of Permanent Income". Mimeo.

Aaberge, R., A. Björklund, M. Jäntti, M. Palme, P. J. Pedersen, N. Smith and T. Wennemo (2002): "Income Inequality and Income Mobility in the Scandinavian Countries Compared to the United States", Review of Income and Wealth, 48 (4)

Alstadsæter, A. and E. Fjærli (2009): "Neutral Taxation of Shareholder Income? Corporate Responses to an Announced Dividend Tax". International Tax and Public Finance, 16, 571-604.

Atkinson, A. B. and T. Piketty (Eds.) (2007): Top Incomes over the 20th Century: A Contrast between European and English-Speaking Countries. Oxford University Press, Oxford.

Atkinson, A. B. and T. Piketty (Eds.) (2010): Top Incomes A Global Perspective, Oxford University Press, Oxford, 448-482.

Auten, G., Gee, G., Turner, N. (2013). "Income Inequality, Mobility and Turnover at the Top in the U.S., 1987 - 2010", AER Papers and Proceedings.

Björklund, A., J. Roine and D. Waldenström (2012): "Intergenerational Top Income Mobility in Sweden: Capitalist Dynasties in the Land of equal Opportunity?" Journal of Public Economics 96 (56), pp. 474-484. 
Kopczuk, W., E. Saez and J. Song (2010): "Earnings Inequality and Mobility in the United States: Evidence from Social Security Data since 1937”, Quarterly Journal of Economics, 125, 91-128.

Saez, E and M R Veall (2007): “The Evolutions of High Incomes in Canada, 1920-2000”. In: Atkinson and Piketty (eds): Top Incomes over the 20th Century. Oxford University Press, Oxford.

Shorrocks, A. (1978): "Income inequality and income mobility". Journal of Economic Theory 19, 376393.

\section{Appendices}

\section{A1. Proof}

LEMMA 1. Let $M$ be the family of bounded, continuous and non-negative functions on $[0,1]$ which are positive on $\langle 0,1\rangle$ and let $g$ be an arbitrary bounded and continuous function on $[0,1]$. Then

$$
\int g(t) h(t) d t>0 \text { for all } h \in M
$$

implies

$$
g(t) \geq 0 \text { for all } t \in[0,1]
$$

and the inequality holds strictly for at least one $t \in\langle 0,1\rangle$.

The proof of Lemma 1 is known from mathematical textbooks.

\section{Proof of Theorem 2.1.}

Using integration by parts and the fact that $q^{\prime}(u)=q(u)=0$ we have that

$0<\theta_{q}\left(u ; T_{1}\right)-\theta_{q}\left(u ; T_{2}\right)=\int_{u}^{l} q(s) d\left(T_{2}(s)-T_{1}(s)\right)=\int_{u}^{l} q^{\prime}(s)\left(T_{1}(s)-T_{2}(s)\right) d s=\int_{u}^{l} q^{\prime \prime}(v) \int_{v}^{l}\left(T_{1}(s)-T_{2}(s)\right) d s d v$

Thus, if (i) holds then $\theta_{q}\left(u ; T_{1}\right)>\theta_{q}\left(u ; T_{2}\right)$ for all positive non-decreasing convex $q$.

To prove the converse statement we restrict attention to all positive non-decreasing convex $q$ where $q^{\prime}(u)=q(u)=0$. Hence, 


$$
0<\theta_{q}\left(u ; T_{1}\right)-\theta_{q}\left(u ; T_{2}\right)=\int_{u}^{l} q^{\prime}(v) \int_{v}^{l}\left(T_{1}(s)-T_{2}(s)\right) d s d v
$$

and the desired result it obtained by applying Lemma 1 . 


\section{A2. Figure appendix}

Figure 12. Income mobility curve, entire distribution, three-year windows, 2004-2008

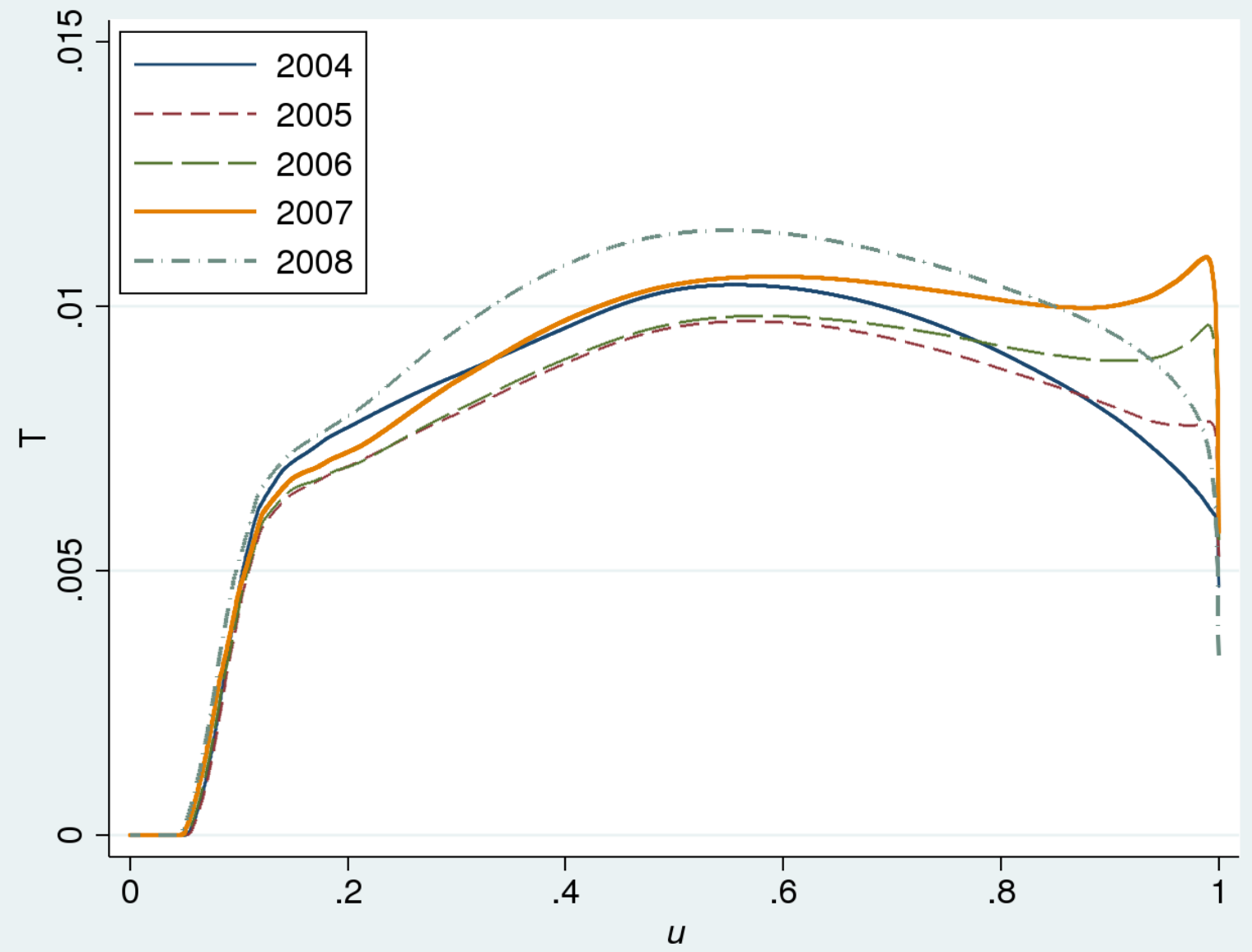


Figure 13. Mobility, decomposed (MG refers to partial mobility, bounded at top and bottom)

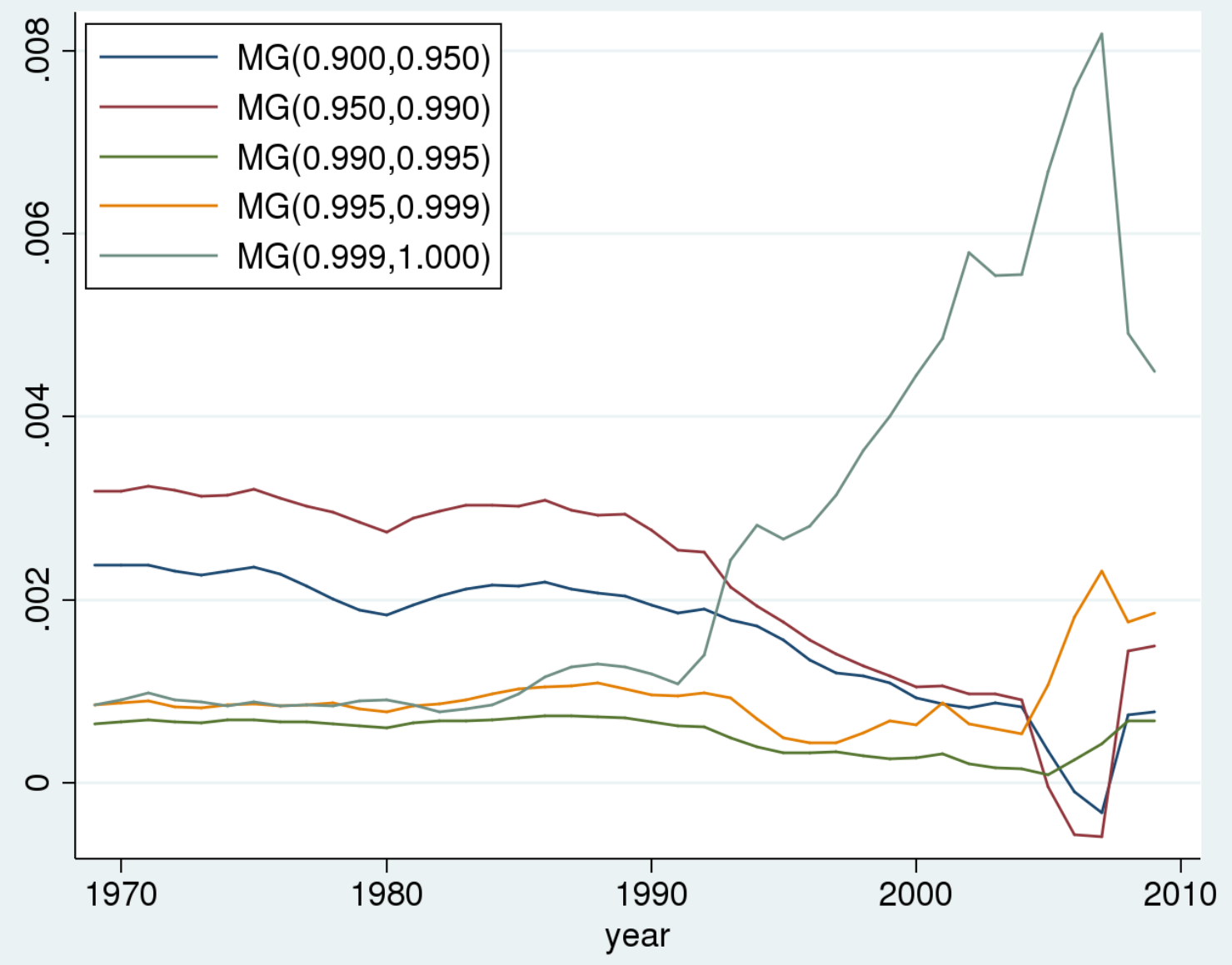


Figure 14: Cohorts, top $0.1 \%(u=0.999)$

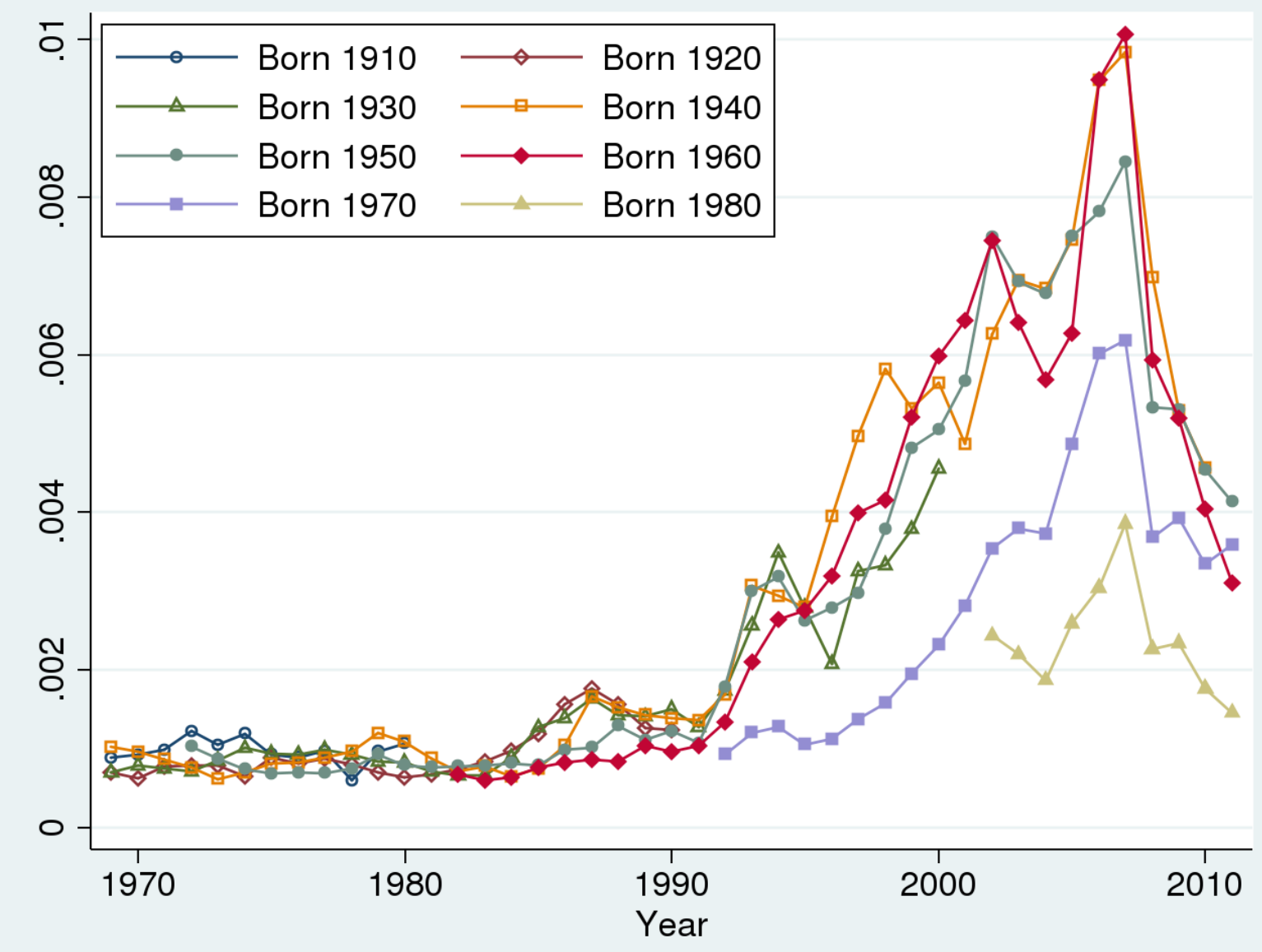


Figure 15. Top income shares within cohort, top $5 \%$

\section{Top income shares}
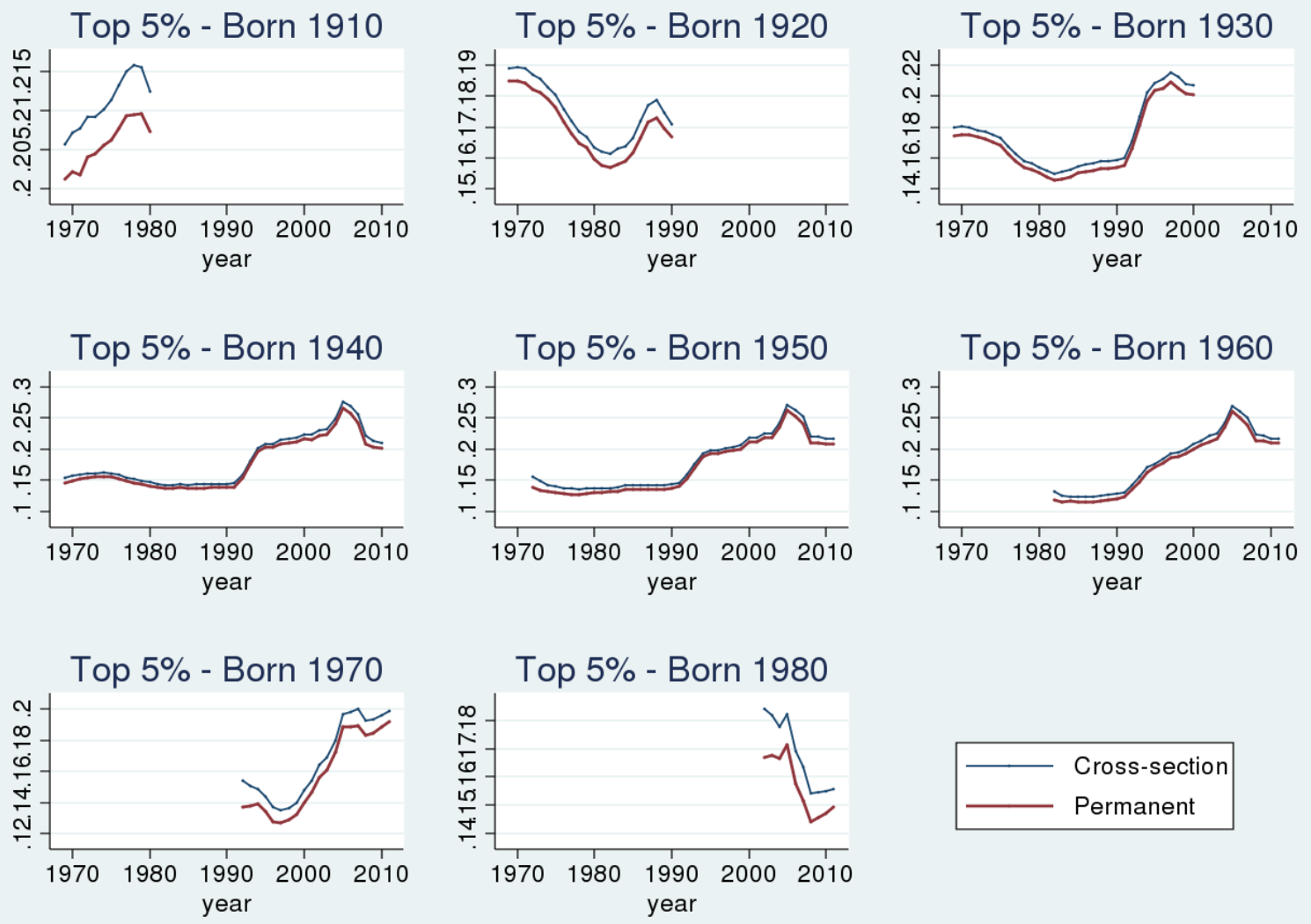
Figure 16. Top income share within cohort, top $0.1 \%$

\section{Top income shares}
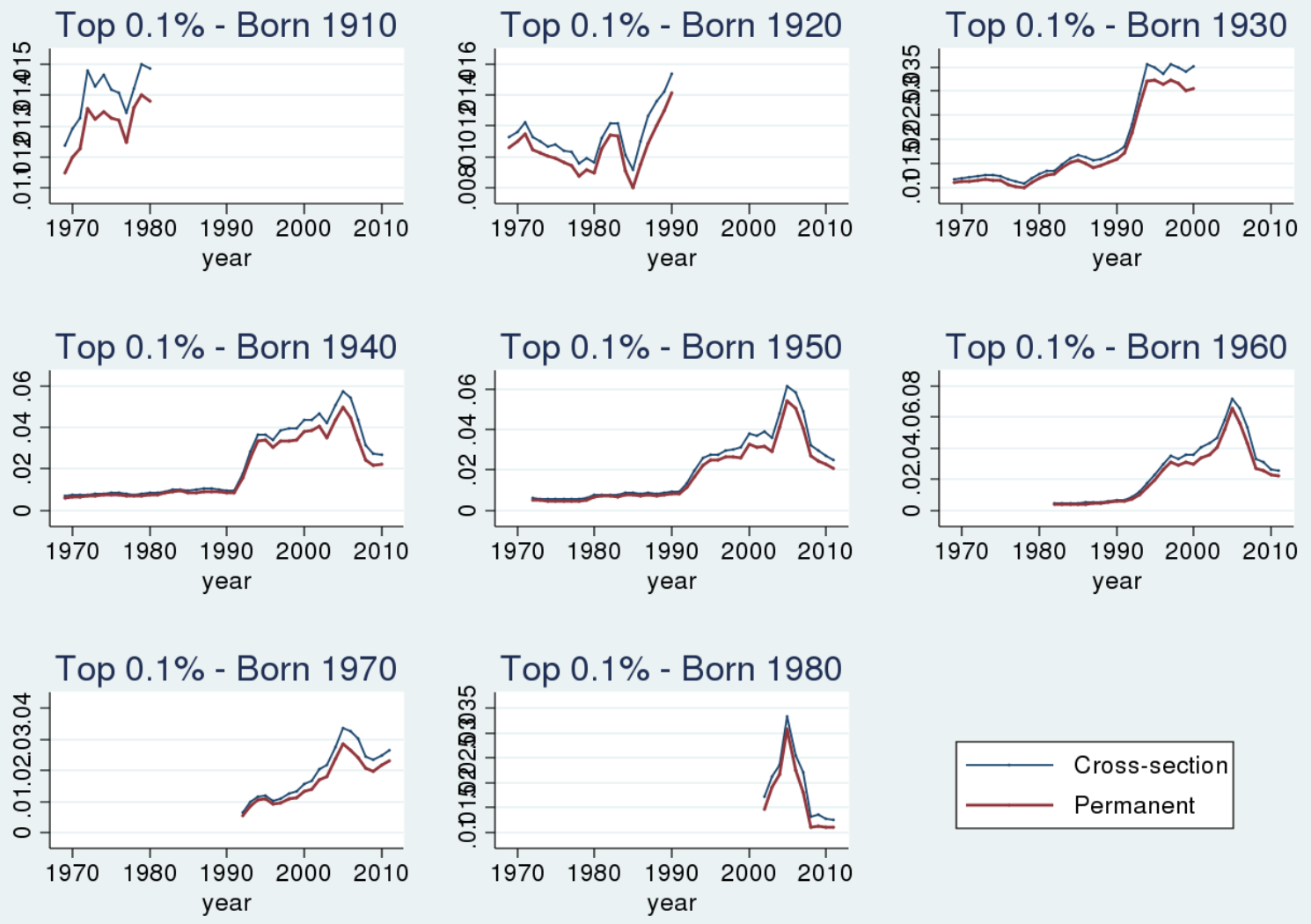

\section{A3. Tables}

Table A1. Top income mobility, three-year moving averages

\begin{tabular}{|c|c|c|c|c|c|c|c|c|c|c|}
\hline & \multicolumn{5}{|c|}{$T(u)$ - Top income mobility curve } & \multicolumn{5}{|c|}{$T^{\prime}(u)$ - Derivative of top income mobility curve } \\
\hline & 0.9 & 0.95 & 0.99 & 0.995 & 0.999 & 0.9 & 0.95 & 0.99 & 0.995 & 0.999 \\
\hline 1969 & $0,790 \%$ & $0,552 \%$ & $0,234 \%$ & $0,170 \%$ & $0,085 \%$ & $-3,73 \%$ & $-6,17 \%$ & $-11,60 \%$ & $-14,79 \%$ & $-36,05 \%$ \\
\hline 1970 & $0,800 \%$ & $0,562 \%$ & $0,243 \%$ & $0,177 \%$ & $0,090 \%$ & $-3,83 \%$ & $-6,23 \%$ & $-11,30 \%$ & $-15,89 \%$ & $-37,01 \%$ \\
\hline 1971 & $0,817 \%$ & $0,579 \%$ & $0,255 \%$ & $0,186 \%$ & $0,097 \%$ & $-3,82 \%$ & $-6,16 \%$ & $-12,16 \%$ & $-16,73 \%$ & $-37,08 \%$ \\
\hline 1972 & $0,790 \%$ & $0,559 \%$ & $0,239 \%$ & $0,173 \%$ & $0,090 \%$ & $-3,80 \%$ & $-5,92 \%$ & $-11,54 \%$ & $-16,46 \%$ & $-31,97 \%$ \\
\hline 1973 & $0,775 \%$ & $0,548 \%$ & $0,235 \%$ & $0,169 \%$ & $0,088 \%$ & $-3,74 \%$ & $-5,88 \%$ & $-10,94 \%$ & $-16,12 \%$ & $-29,87 \%$ \\
\hline 1974 & $0,782 \%$ & $0,551 \%$ & $0,236 \%$ & $0,168 \%$ & $0,083 \%$ & $-3,78 \%$ & $-5,82 \%$ & $-11,37 \%$ & $-18,29 \%$ & $-30,97 \%$ \\
\hline
\end{tabular}




\begin{tabular}{|c|c|c|c|c|c|c|c|c|c|c|}
\hline 1975 & 0,799 \% & $0,563 \%$ & $0,242 \%$ & $0,174 \%$ & $0,088 \%$ & $-3,76 \%$ & $-5,99 \%$ & $-11,50 \%$ & $-16,92 \%$ & $-32,49 \%$ \\
\hline 1976 & $0,771 \%$ & $0,544 \%$ & $0,233 \%$ & $0,167 \%$ & $0,083 \%$ & $-3,62 \%$ & $-5,84 \%$ & $-11,62 \%$ & $-16,02 \%$ & $-34,21 \%$ \\
\hline 1977 & $0,752 \%$ & $0,537 \%$ & $0,236 \%$ & $0,170 \%$ & $0,084 \%$ & $-3,46 \%$ & $-5,59 \%$ & $-11,29 \%$ & $-15,03 \%$ & $-36,05 \%$ \\
\hline 1978 & $0,730 \%$ & $0,530 \%$ & $0,234 \%$ & $0,170 \%$ & $0,084 \%$ & $-3,04 \%$ & $-5,47 \%$ & $-11,15 \%$ & $-15,47 \%$ & $-37,56 \%$ \\
\hline 1979 & $0,705 \%$ & $0,516 \%$ & $0,231 \%$ & $0,169 \%$ & $0,089 \%$ & $-2,97 \%$ & $-4,97 \%$ & $-10,90 \%$ & $-14,61 \%$ & $-34,87 \%$ \\
\hline 1980 & $0,683 \%$ & $0,500 \%$ & $0,227 \%$ & $0,167 \%$ & $0,090 \%$ & $-2,86 \%$ & $-4,87 \%$ & $-10,56 \%$ & $-14,44 \%$ & $-34,02 \%$ \\
\hline 1981 & $0,716 \%$ & $0,522 \%$ & $0,232 \%$ & $0,168 \%$ & $0,084 \%$ & $-3,03 \%$ & $-5,18 \%$ & $-11,53 \%$ & $-15,68 \%$ & $-36,34 \%$ \\
\hline 1982 & $0,729 \%$ & $0,526 \%$ & $0,230 \%$ & $0,163 \%$ & $0,077 \%$ & $-3,36 \%$ & $-5,31 \%$ & $-11,78 \%$ & $-15,53 \%$ & $-32,30 \%$ \\
\hline 1983 & 0,751 \% & $0,539 \%$ & $0,237 \%$ & $0,170 \%$ & $0,080 \%$ & $-3,46 \%$ & $-5,35 \%$ & $-11,55 \%$ & $-16,20 \%$ & $-35,86 \%$ \\
\hline 1984 & 0,768 \% & $0,552 \%$ & $0,249 \%$ & $0,181 \%$ & $0,084 \%$ & $-3,52 \%$ & $-5,41 \%$ & $-12,13 \%$ & $-16,13 \%$ & $-39,47 \%$ \\
\hline 1985 & $0,786 \%$ & $0,571 \%$ & $0,270 \%$ & 0,199 \% & $0,097 \%$ & $-3,58 \%$ & $-5,42 \%$ & $-12,12 \%$ & $-17,03 \%$ & $-43,48 \%$ \\
\hline 1986 & $0,819 \%$ & $0,600 \%$ & $0,292 \%$ & $0,220 \%$ & $0,115 \%$ & $-3,71 \%$ & $-5,54 \%$ & $-12,48 \%$ & $-17,76 \%$ & $-45,12 \%$ \\
\hline 1987 & $0,813 \%$ & $0,602 \%$ & $0,304 \%$ & $0,232 \%$ & $0,126 \%$ & $-3,55 \%$ & $-5,36 \%$ & $-12,09 \%$ & $-17,59 \%$ & $-45,69 \%$ \\
\hline 1988 & $0,809 \%$ & $0,603 \%$ & $0,310 \%$ & $0,238 \%$ & $0,129 \%$ & $-3,46 \%$ & $-5,21 \%$ & $-12,08 \%$ & $-18,35 \%$ & $-51,63 \%$ \\
\hline 1989 & $0,796 \%$ & $0,592 \%$ & $0,299 \%$ & $0,228 \%$ & $0,126 \%$ & $-3,44 \%$ & $-5,13 \%$ & $-12,29 \%$ & $-16,98 \%$ & $-49,40 \%$ \\
\hline 1990 & $0,752 \%$ & $0,558 \%$ & $0,282 \%$ & $0,215 \%$ & $0,119 \%$ & $-3,33 \%$ & $-4,86 \%$ & $-11,41 \%$ & $-16,29 \%$ & $-44,59 \%$ \\
\hline 1991 & 0,703 \% & $0,518 \%$ & $0,264 \%$ & $0,202 \%$ & $0,108 \%$ & $-3,14 \%$ & $-4,56 \%$ & $-10,13 \%$ & $-15,87 \%$ & $-41,67 \%$ \\
\hline 1992 & $0,739 \%$ & $0,550 \%$ & $0,298 \%$ & $0,237 \%$ & $0,139 \%$ & $-3,08 \%$ & $-4,81 \%$ & $-10,32 \%$ & $-15,78 \%$ & $-44,35 \%$ \\
\hline 1993 & $0,775 \%$ & $0,598 \%$ & $0,384 \%$ & $0,335 \%$ & $0,243 \%$ & $-2,95 \%$ & $-4,37 \%$ & $-8,20 \%$ & $-12,65 \%$ & $-57,76 \%$ \\
\hline 1994 & $0,756 \%$ & $0,584 \%$ & 0,391 \% & $0,352 \%$ & $0,282 \%$ & $-2,89 \%$ & $-4,06 \%$ & $-6,78 \%$ & $-10,37 \%$ & $-34,70 \%$ \\
\hline 1995 & $0,680 \%$ & $0,524 \%$ & $0,348 \%$ & $0,315 \%$ & $0,266 \%$ & $-2,55 \%$ & $-3,68 \%$ & $-5,36 \%$ & $-7,84 \%$ & $-25,92 \%$ \\
\hline 1996 & $0,645 \%$ & $0,512 \%$ & $0,357 \%$ & $0,324 \%$ & $0,281 \%$ & $-2,23 \%$ & $-3,14 \%$ & $-5,39 \%$ & $-7,74 \%$ & $-23,18 \%$ \\
\hline 1997 & $0,651 \%$ & $0,531 \%$ & 0,391 \% & $0,358 \%$ & $0,314 \%$ & $-2,00 \%$ & $-2,79 \%$ & $-5,22 \%$ & $-7,89 \%$ & $-22,34 \%$ \\
\hline 1998 & $0,691 \%$ & $0,575 \%$ & $0,448 \%$ & $0,418 \%$ & $0,364 \%$ & $-2,05 \%$ & $-2,72 \%$ & $-4,90 \%$ & $-7,09 \%$ & $-36,21 \%$ \\
\hline 1999 & 0,719 \% & $0,610 \%$ & $0,494 \%$ & $0,468 \%$ & $0,400 \%$ & $-1,86 \%$ & $-2,47 \%$ & $-4,44 \%$ & $-7,20 \%$ & $-52,34 \%$ \\
\hline 2000 & $0,731 \%$ & $0,639 \%$ & $0,534 \%$ & $0,508 \%$ & $0,445 \%$ & $-1,58 \%$ & $-2,20 \%$ & $-4,40 \%$ & $-7,53 \%$ & $-53,44 \%$ \\
\hline 2001 & $0,795 \%$ & $0,709 \%$ & $0,603 \%$ & $0,573 \%$ & $0,485 \%$ & $-1,50 \%$ & $-2,01 \%$ & $-4,59 \%$ & $-8,79 \%$ & $-80,10 \%$ \\
\hline 2002 & $0,843 \%$ & $0,761 \%$ & $0,664 \%$ & $0,644 \%$ & $0,580 \%$ & $-1,35 \%$ & $-1,88 \%$ & $-3,23 \%$ & $-5,02 \%$ & $-73,66 \%$ \\
\hline 2003 & $0,813 \%$ & $0,726 \%$ & $0,630 \%$ & $0,613 \%$ & $0,555 \%$ & $-1,49 \%$ & $-2,11 \%$ & $-3,58 \%$ & $-4,30 \%$ & $-64,97 \%$ \\
\hline 2004 & 0,796 \% & $0,713 \%$ & $0,623 \%$ & $0,608 \%$ & $0,555 \%$ & $-1,38 \%$ & $-1,89 \%$ & $-2,73 \%$ & $-2,51 \%$ & $-46,00 \%$ \\
\hline 2005 & $0,812 \%$ & $0,778 \%$ & $0,782 \%$ & $0,774 \%$ & $0,668 \%$ & $-0,77 \%$ & $-0,38 \%$ & $-0,06 \%$ & $-3,55 \%$ & $-116,61 \%$ \\
\hline 2006 & $0,897 \%$ & $0,907 \%$ & $0,964 \%$ & $0,940 \%$ & $0,759 \%$ & $-0,04 \%$ & $0,72 \%$ & $0,07 \%$ & $-11,62 \%$ & $-163,41 \%$ \\
\hline 2007 & $1,000 \%$ & $1,033 \%$ & $1,092 \%$ & $1,050 \%$ & $0,819 \%$ & $0,30 \%$ & $1,18 \%$ & $-1,95 \%$ & $-19,09 \%$ & $-200,72 \%$ \\
\hline 2008 & $0,951 \%$ & $0,877 \%$ & $0,734 \%$ & $0,667 \%$ & $0,491 \%$ & $-1,13 \%$ & $-1,96 \%$ & $-8,98 \%$ & $-20,92 \%$ & $-123,68 \%$ \\
\hline 2009 & 0,927 \% & $0,850 \%$ & 0,701 \% & $0,634 \%$ & $0,449 \%$ & $-1,24 \%$ & $-2,03 \%$ & $-9,33 \%$ & $-21,49 \%$ & $-124,97 \%$ \\
\hline 2010 & $0,815 \%$ & $0,730 \%$ & $0,592 \%$ & $0,533 \%$ & $0,375 \%$ & $-1,41 \%$ & $-2,11 \%$ & $-8,14 \%$ & $-18,98 \%$ & $-103,48 \%$ \\
\hline 2011 & $0,721 \%$ & $0,656 \%$ & $0,539 \%$ & $0,481 \%$ & $0,320 \%$ & $-1,13 \%$ & $-1,59 \%$ & $-7,57 \%$ & $-17,01 \%$ & $-96,83 \%$ \\
\hline
\end{tabular}


Table A2. Top income shares, three-year moving averages

\begin{tabular}{|c|c|c|c|c|c|c|c|c|c|c|}
\hline & \multicolumn{2}{|c|}{ Top $10 \%(u=0.9)$} & \multicolumn{2}{|c|}{ Top 5 \% (u=0.95) } & \multicolumn{2}{|c|}{ Top $1 \%(u=0.99)$} & \multicolumn{2}{|c|}{ Top $0.5 \%$ (u=0.995) } & \multicolumn{2}{|c|}{ Top $0.1 \%$ (u=0.999) } \\
\hline & Cross-sect. & Permanent & Cross-sect. & Permanent & Cross-sect. & Permanent & Cross-sect. & Permanent & Cross-sect. & Permanent \\
\hline 1969 & $33,69 \%$ & $32,90 \%$ & $20,49 \%$ & $19,94 \%$ & $6,36 \%$ & $6,12 \%$ & $3,84 \%$ & $3,67 \%$ & $1,24 \%$ & $1,16 \%$ \\
\hline 1970 & $33,55 \%$ & $32,75 \%$ & $20,47 \%$ & $19,91 \%$ & $6,43 \%$ & $6,19 \%$ & $3,92 \%$ & $3,74 \%$ & $1,29 \%$ & $1,20 \%$ \\
\hline 1971 & $33,23 \%$ & $32,41 \%$ & $20,31 \%$ & $19,74 \%$ & $6,43 \%$ & $6,18 \%$ & $3,94 \%$ & $3,75 \%$ & $1,31 \%$ & $1,21 \%$ \\
\hline 1972 & $32,83 \%$ & $32,04 \%$ & $20,06 \%$ & $19,50 \%$ & $6,36 \%$ & $6,12 \%$ & $3,90 \%$ & $3,73 \%$ & $1,30 \%$ & $1,21 \%$ \\
\hline 1973 & $32,43 \%$ & $31,66 \%$ & $19,79 \%$ & $19,24 \%$ & $6,25 \%$ & $6,02 \%$ & $3,83 \%$ & $3,66 \%$ & $1,27 \%$ & $1,18 \%$ \\
\hline 1974 & $32,07 \%$ & $31,29 \%$ & $19,53 \%$ & $18,98 \%$ & $6,15 \%$ & $5,91 \%$ & $3,77 \%$ & $3,60 \%$ & $1,25 \%$ & $1,17 \%$ \\
\hline 1975 & $31,72 \%$ & $30,92 \%$ & $19,24 \%$ & $18,68 \%$ & $6,02 \%$ & $5,78 \%$ & $3,67 \%$ & $3,50 \%$ & $1,21 \%$ & $1,13 \%$ \\
\hline 1976 & $31,08 \%$ & $30,30 \%$ & $18,71 \%$ & $18,17 \%$ & $5,76 \%$ & $5,53 \%$ & $3,49 \%$ & $3,32 \%$ & $1,14 \%$ & $1,05 \%$ \\
\hline 1977 & $30,33 \%$ & $29,58 \%$ & $18,16 \%$ & $17,62 \%$ & $5,50 \%$ & $5,27 \%$ & $3,31 \%$ & $3,14 \%$ & $1,05 \%$ & $0,97 \%$ \\
\hline 1978 & $29,56 \%$ & $28,83 \%$ & $17,65 \%$ & $17,12 \%$ & $5,31 \%$ & $5,07 \%$ & $3,18 \%$ & $3,01 \%$ & $1,00 \%$ & $0,91 \%$ \\
\hline 1979 & $28,95 \%$ & $28,24 \%$ & $17,29 \%$ & $16,77 \%$ & $5,23 \%$ & $4,99 \%$ & $3,15 \%$ & $2,98 \%$ & $1,01 \%$ & $0,92 \%$ \\
\hline 1980 & $28,22 \%$ & $27,53 \%$ & $16,83 \%$ & $16,33 \%$ & $5,09 \%$ & $4,87 \%$ & $3,08 \%$ & $2,91 \%$ & $1,01 \%$ & $0,92 \%$ \\
\hline 1981 & $27,62 \%$ & $26,91 \%$ & $16,45 \%$ & $15,92 \%$ & $4,96 \%$ & $4,73 \%$ & $3,00 \%$ & $2,83 \%$ & $1,00 \%$ & $0,91 \%$ \\
\hline 1982 & $27,17 \%$ & $26,44 \%$ & $16,13 \%$ & $15,60 \%$ & $4,84 \%$ & $4,61 \%$ & $2,92 \%$ & $2,76 \%$ & $0,99 \%$ & $0,91 \%$ \\
\hline 1983 & $27,15 \%$ & $26,40 \%$ & $16,13 \%$ & $15,59 \%$ & $4,85 \%$ & $4,61 \%$ & $2,94 \%$ & $2,77 \%$ & $1,01 \%$ & $0,93 \%$ \\
\hline 1984 & $27,20 \%$ & $26,43 \%$ & $16,18 \%$ & $15,63 \%$ & $4,89 \%$ & $4,65 \%$ & $2,98 \%$ & $2,80 \%$ & $1,04 \%$ & $0,96 \%$ \\
\hline 1985 & $27,23 \%$ & $26,44 \%$ & $16,25 \%$ & $15,68 \%$ & $4,95 \%$ & $4,68 \%$ & $3,02 \%$ & $2,83 \%$ & $1,06 \%$ & $0,96 \%$ \\
\hline 1986 & $27,15 \%$ & $26,34 \%$ & $16,26 \%$ & $15,66 \%$ & $5,00 \%$ & $4,71 \%$ & $3,07 \%$ & $2,85 \%$ & $1,09 \%$ & $0,97 \%$ \\
\hline 1987 & $27,01 \%$ & $26,20 \%$ & $16,23 \%$ & $15,63 \%$ & $5,04 \%$ & $4,74 \%$ & $3,12 \%$ & $2,88 \%$ & $1,12 \%$ & $0,99 \%$ \\
\hline 1988 & $26,73 \%$ & $25,92 \%$ & $16,10 \%$ & $15,49 \%$ & $5,02 \%$ & $4,71 \%$ & $3,11 \%$ & $2,87 \%$ & $1,11 \%$ & $0,98 \%$ \\
\hline 1989 & $26,29 \%$ & $25,49 \%$ & $15,84 \%$ & $15,25 \%$ & $4,94 \%$ & $4,64 \%$ & $3,05 \%$ & $2,82 \%$ & $1,08 \%$ & $0,95 \%$ \\
\hline 1990 & $25,96 \%$ & $25,20 \%$ & $15,67 \%$ & $15,11 \%$ & $4,90 \%$ & $4,62 \%$ & $3,02 \%$ & $2,81 \%$ & $1,05 \%$ & $0,93 \%$ \\
\hline 1991 & $25,94 \%$ & $25,24 \%$ & $15,72 \%$ & $15,20 \%$ & $4,96 \%$ & $4,69 \%$ & $3,06 \%$ & $2,86 \%$ & $1,06 \%$ & $0,95 \%$ \\
\hline 1992 & $27,00 \%$ & $26,26 \%$ & $16,67 \%$ & $16,13 \%$ & $5,56 \%$ & $5,26 \%$ & $3,54 \%$ & $3,30 \%$ & $1,33 \%$ & $1,19 \%$ \\
\hline 1993 & $28,59 \%$ & $27,82 \%$ & $18,21 \%$ & $17,61 \%$ & $6,71 \%$ & $6,33 \%$ & $4,52 \%$ & $4,19 \%$ & $1,95 \%$ & $1,71 \%$ \\
\hline 1994 & $30,09 \%$ & $29,34 \%$ & $19,68 \%$ & $19,10 \%$ & $7,84 \%$ & $7,45 \%$ & $5,49 \%$ & $5,14 \%$ & $2,56 \%$ & $2,28 \%$ \\
\hline 1995 & $30,56 \%$ & $29,88 \%$ & $20,24 \%$ & $19,72 \%$ & $8,37 \%$ & $8,02 \%$ & $5,97 \%$ & $5,65 \%$ & $2,90 \%$ & $2,63 \%$ \\
\hline 1996 & $30,63 \%$ & $29,98 \%$ & $20,38 \%$ & $19,87 \%$ & $8,53 \%$ & $8,17 \%$ & $6,13 \%$ & $5,81 \%$ & $3,05 \%$ & $2,77 \%$ \\
\hline 1997 & $30,84 \%$ & $30,19 \%$ & $20,67 \%$ & $20,14 \%$ & $8,81 \%$ & $8,42 \%$ & $6,40 \%$ & $6,04 \%$ & $3,28 \%$ & $2,97 \%$ \\
\hline 1998 & $30,81 \%$ & $30,11 \%$ & $20,73 \%$ & $20,15 \%$ & $8,91 \%$ & $8,46 \%$ & $6,49 \%$ & $6,07 \%$ & $3,33 \%$ & $2,96 \%$ \\
\hline 1999 & $30,83 \%$ & $30,11 \%$ & $20,82 \%$ & $20,21 \%$ & $9,03 \%$ & $8,53 \%$ & $6,58 \%$ & $6,12 \%$ & $3,36 \%$ & $2,96 \%$ \\
\hline 2000 & $31,47 \%$ & $30,74 \%$ & $21,53 \%$ & $20,90 \%$ & $9,71 \%$ & $9,17 \%$ & $7,21 \%$ & $6,70 \%$ & $3,79 \%$ & $3,34 \%$ \\
\hline 2001 & $31,51 \%$ & $30,71 \%$ & $21,51 \%$ & $20,80 \%$ & $9,58 \%$ & $8,98 \%$ & $7,07 \%$ & $6,49 \%$ & $3,67 \%$ & $3,18 \%$ \\
\hline 2002 & $32,18 \%$ & $31,33 \%$ & $22,19 \%$ & $21,42 \%$ & $10,20 \%$ & $9,54 \%$ & $7,65 \%$ & $7,01 \%$ & $4,14 \%$ & $3,56 \%$ \\
\hline 2003 & $32,42 \%$ & $31,61 \%$ & $22,44 \%$ & $21,71 \%$ & $10,43 \%$ & $9,80 \%$ & $7,86 \%$ & $7,25 \%$ & $4,30 \%$ & $3,74 \%$ \\
\hline 2004 & $33,75 \%$ & $32,95 \%$ & $23,88 \%$ & $23,17 \%$ & $11,85 \%$ & $11,23 \%$ & $9,21 \%$ & $8,60 \%$ & $5,36 \%$ & $4,80 \%$ \\
\hline 2005 & $36,09 \%$ & $35,27 \%$ & $26,37 \%$ & $25,59 \%$ & $14,18 \%$ & $13,39 \%$ & $11,29 \%$ & $10,52 \%$ & $6,74 \%$ & $6,07 \%$ \\
\hline 2006 & $35,39 \%$ & $34,49 \%$ & $25,48 \%$ & $24,58 \%$ & $13,17 \%$ & $12,20 \%$ & $10,32 \%$ & $9,38 \%$ & $5,98 \%$ & $5,23 \%$ \\
\hline 2007 & $34,77 \%$ & $33,77 \%$ & $24,66 \%$ & $23,63 \%$ & $12,13 \%$ & $11,04 \%$ & $9,28 \%$ & $8,23 \%$ & $5,07 \%$ & $4,26 \%$ \\
\hline 2008 & $32,31 \%$ & $31,36 \%$ & $21,87 \%$ & $20,99 \%$ & $9,24 \%$ & $8,51 \%$ & $6,58 \%$ & $5,91 \%$ & $3,08 \%$ & $2,59 \%$ \\
\hline 2009 & $32,30 \%$ & $31,37 \%$ & $21,78 \%$ & $20,93 \%$ & $9,07 \%$ & $8,36 \%$ & $6,39 \%$ & $5,76 \%$ & $2,92 \%$ & $2,47 \%$ \\
\hline 2010 & $32,08 \%$ & $31,27 \%$ & $21,52 \%$ & $20,79 \%$ & $8,80 \%$ & $8,21 \%$ & $6,15 \%$ & $5,62 \%$ & $2,77 \%$ & $2,40 \%$ \\
\hline 2011 & $32,05 \%$ & $31,33 \%$ & $21,44 \%$ & $20,79 \%$ & $8,70 \%$ & $8,17 \%$ & $6,06 \%$ & $5,58 \%$ & $2,71 \%$ & $2,39 \%$ \\
\hline
\end{tabular}


Table A3. Summary measures of top income mobility

\begin{tabular}{|c|c|c|c|c|c|c|c|c|c|c|c|c|}
\hline & \multicolumn{3}{|c|}{$u=0.50$} & \multicolumn{3}{|c|}{$u=0.80$} & \multicolumn{3}{|c|}{$u=0.90$} & \multicolumn{3}{|c|}{$u=0.99$} \\
\hline & $\tilde{\theta}_{1}$ & $\tilde{\theta}_{2}$ & $\tilde{\theta}_{3}$ & $\tilde{\theta}_{1}$ & $\tilde{\theta}_{2}$ & $\tilde{\theta}_{3}$ & $\tilde{\theta}_{1}$ & $\tilde{\theta}_{2}$ & $\tilde{\theta}_{3}$ & $\tilde{\theta}_{1}$ & $\tilde{\theta}_{2}$ & $\tilde{\theta}_{3}$ \\
\hline 1969 & 0,036 & 0,047 & 0,056 & 0,055 & 0,074 & 0,088 & 0,079 & 0,104 & 0,123 & 0,234 & 0,321 & 0,395 \\
\hline 1970 & 0,036 & 0,047 & 0,056 & 0,055 & 0,074 & 0,090 & 0,080 & 0,106 & 0,126 & 0,243 & 0,335 & 0,412 \\
\hline 1971 & 0,036 & 0,047 & 0,057 & 0,056 & 0,076 & 0,092 & 0,082 & 0,109 & 0,130 & 0,255 & 0,355 & 0,439 \\
\hline 1972 & 0,034 & 0,046 & 0,055 & 0,054 & 0,074 & 0,089 & 0,079 & 0,105 & 0,125 & 0,239 & 0,330 & 0,407 \\
\hline 1973 & 0,033 & 0,045 & 0,055 & 0,053 & 0,072 & 0,087 & 0,077 & 0,103 & 0,122 & 0,235 & 0,323 & 0,398 \\
\hline 1974 & 0,033 & 0,046 & 0,055 & 0,053 & 0,073 & 0,087 & 0,078 & 0,103 & 0,123 & 0,236 & 0,320 & 0,390 \\
\hline 1975 & 0,033 & 0,046 & 0,056 & 0,054 & 0,074 & 0,089 & 0,080 & 0,106 & 0,126 & 0,242 & 0,331 & 0,405 \\
\hline 1976 & 0,032 & 0,045 & 0,054 & 0,052 & 0,072 & 0,086 & 0,077 & 0,102 & 0,122 & 0,233 & 0,318 & 0,388 \\
\hline 1977 & 0,031 & 0,043 & 0,052 & 0,051 & 0,070 & 0,085 & 0,075 & 0,101 & 0,121 & 0,236 & 0,323 & 0,395 \\
\hline 1978 & 0,030 & 0,041 & 0,050 & 0,049 & 0,068 & 0,083 & 0,073 & 0,099 & 0,119 & 0,234 & 0,322 & 0,395 \\
\hline 1979 & 0,028 & 0,039 & 0,048 & 0,046 & 0,065 & 0,080 & 0,070 & 0,096 & 0,117 & 0,231 & 0,322 & 0,399 \\
\hline 1980 & 0,028 & 0,038 & 0,046 & 0,045 & 0,063 & 0,078 & 0,068 & 0,094 & 0,113 & 0,227 & 0,319 & 0,397 \\
\hline 1981 & 0,029 & 0,040 & 0,049 & 0,048 & 0,067 & 0,081 & 0,072 & 0,097 & 0,118 & 0,232 & 0,318 & 0,389 \\
\hline 1982 & 0,030 & 0,041 & 0,050 & 0,049 & 0,068 & 0,083 & 0,073 & 0,098 & 0,118 & 0,230 & 0,308 & 0,374 \\
\hline 1983 & 0,031 & 0,043 & 0,052 & 0,051 & 0,070 & 0,085 & 0,075 & 0,101 & 0,121 & 0,237 & 0,320 & 0,389 \\
\hline 1984 & 0,031 & 0,044 & 0,054 & 0,053 & 0,072 & 0,087 & 0,077 & 0,104 & 0,125 & 0,249 & 0,339 & 0,412 \\
\hline 1985 & 0,031 & 0,044 & 0,055 & 0,054 & 0,074 & 0,090 & 0,079 & 0,107 & 0,131 & 0,270 & 0,373 & 0,458 \\
\hline 1986 & 0,032 & 0,046 & 0,057 & 0,056 & 0,077 & 0,094 & 0,082 & 0,113 & 0,138 & 0,292 & 0,414 & 0,515 \\
\hline 1987 & & 0,045 & & & & & & & & & & \\
\hline 1988 & 0,031 & 0,045 & 0,056 & 0,054 & 0,076 & 0,094 & 0,081 & 0,114 & 0,141 & 0,310 & 0,448 & 0,564 \\
\hline 1989 & 0,029 & 0,044 & 0,054 & 0,053 & 0,075 & 0,093 & 0,080 & 0,112 & 0,138 & 0,299 & 0,432 & 0,546 \\
\hline 1990 & 0,028 & 0,041 & 0,052 & 0,051 & 0,071 & 0,088 & 0,075 & 0,105 & 0,130 & 0,282 & 0,407 & 0,514 \\
\hline 1991 & 0,027 & 0,039 & 0,049 & 0,048 & 0,066 & 0,082 & 0,070 & 0,098 & 0,121 & 0,264 & 0,381 & 0,479 \\
\hline 1992 & 0,026 & 0,040 & 0,050 & 0,049 & 0,070 & 0,087 & 0,074 & 0,105 & 0,131 & 0,298 & 0,447 & 0,576 \\
\hline 1993 & 0,025 & 0,040 & 0,052 & 0,050 & 0,074 & 0,094 & 0,078 & 0,116 & 0,150 & 0,384 & 0,639 & 0,870 \\
\hline 1994 & 0,024 & 0,039 & 0,051 & 0,049 & 0,072 & 0,093 & 0,076 & 0,114 & 0,149 & 0,391 & 0,679 & 0,946 \\
\hline 1995 & 0,022 & 0,035 & 0,046 & 0,044 & 0,065 & 0,083 & 0,068 & 0,102 & 0,134 & 0,348 & 0,613 & 0,865 \\
\hline 1996 & 0,021 & 0,033 & 0,043 & 0,041 & 0,062 & 0,081 & 0,065 & 0,100 & 0,133 & 0,357 & 0,635 & 0,901 \\
\hline 1997 & 0,020 & 0,033 & 0,043 & 0,041 & 0,063 & 0,083 & 0,065 & 0,104 & 0,141 & 0,391 & 0,703 & 1,002 \\
\hline 1998 & 0,021 & 0,034 & 0,045 & 0,042 & 0,067 & 0,090 & 0,069 & 0,113 & 0,155 & 0,448 & 0,814 & 1,161 \\
\hline 1999 & 0,021 & 0,035 & 0,047 & 0,043 & 0,070 & 0,095 & 0,072 & 0,120 & 0,167 & 0,494 & 0,905 & 1,292 \\
\hline 2000 & 0,020 & 0,035 & 0,047 & 0,043 & 0,071 & 0,099 & 0,073 & 0,126 & 0,177 & 0,534 & 0,985 & 1,411 \\
\hline 2001 & 0,022 & 0,037 & 0,051 & 0,046 & 0,078 & 0,109 & 0,080 & 0,139 & 0,197 & 0,603 & 1,106 & 1,575 \\
\hline 2002 & 0,022 & 0,039 & 0,054 & 0,048 & 0,083 & 0,116 & 0,084 & 0,150 & 0,215 & 0,664 & 1,254 & 1,815 \\
\hline 2003 & 0,021 & 0,038 & 0,052 & 0,047 & 0,080 & 0,111 & 0,081 & 0,144 & 0,204 & 0,630 & 1,194 & 1,731 \\
\hline 2004 & 0,021 & 0,037 & 0,051 & 0,046 & 0,078 & 0,110 & 0,080 & 0,141 & 0,202 & 0,623 & 1,190 & 1,736 \\
\hline 2005 & 0,019 & 0,036 & 0,051 & 0,044 & 0,081 & 0,119 & 0,081 & 0,156 & 0,232 & 0,782 & 1,493 & 2,157 \\
\hline 2006 & 0,019 & 0,038 & 0,056 & 0,046 & 0,091 & 0,137 & 0,090 & 0,182 & 0,275 & 0,964 & 1,789 & 2,537 \\
\hline 2007 & 0,021 & 0,041 & 0,062 & 0,051 & 0,102 & 0,154 & 0,100 & 0,206 & 0,312 & 1,092 & 1,987 & 2,789 \\
\hline 2008 & 0,023 & 0,041 & 0,059 & 0,052 & 0,092 & 0,131 & 0,095 & 0,170 & 0,241 & 0,734 & 1,265 & 1,739 \\
\hline 2009 & 0,022 & 0,041 & 0,057 & 0,051 & 0,090 & 0,127 & 0,093 & 0,165 & 0,232 & 0,701 & 1,197 & 1,634 \\
\hline
\end{tabular}




\begin{tabular}{l|lll|lll|lll|lll}
2010 & 0,021 & 0,037 & 0,051 & 0,046 & 0,079 & 0,110 & 0,081 & 0,142 & 0,198 & 0,592 & 1,005 & 1,370 \\
2011 & 0,019 & 0,033 & 0,045 & 0,041 & 0,070 & 0,098 & 0,072 & 0,127 & 0,178 & 0,539 & 0,901 & 1,216
\end{tabular}

\section{A4. New top income shares}

As a part of the work on this paper, the top income shares of Aaberge and Atkinson (2010) have been extended to 2011, the last year for which we have data at the time of writing. In addition, new data from 1892-1903 has been added. This section describes the construction of these data.

Extension to 2011: Total income for the top x per cent is constructed from the income files using "ordinary incomes" in the same way as in Aaberge and Atkinson (2010). Unlike the data used in Section 3 and onwards of this paper, the control total in the long series (as presented in Figure 1 and made available in the Top Incomes Database) is constructed from total household income in the National Accounts (a constant $72 \%$ share of the total). As the National Accounts are periodically revised, this results in a small change in the historical numbers back to 1978. For the years prior to 2002, this difference is always less than 0.4 percentage points. For the latter years the revision is somewhat higher.

New data on 1892 to 1903: Some new income tabulations have been added (see source table below). For some of these, the threshold is too high to reliably estimate the income shares for the top $10 \%$. New control totals, using the same methodology as reported by Aaberge and Atkinson (2010), are given in the table below.

The revised control totals and top income shares reported below and have been submitted to the Top Incomes Database.

Table A4. Sources of top income shares

\begin{tabular}{|lll|} 
Year & \multicolumn{1}{c}{ Source } & Comparison to A\&A (2010) \\
\hline 1875 & Ot. Prp. 11 (1881), pp. 20-25 & Same \\
1888 & St. Prp. 48 (1890), p. 42 and 122 & Revised (new source) \\
1892 & Ot. Prp. 39 (1893), vol. 3B & New source \\
1893 & St. Prp. 91 (1894), vol. 2B & New source \\
1894 & St. Prp. 112 (1895), vol. 2B & New source \\
1895 & St. Prp. 104 (1896), vol. 2B & New source \\
1896 & St. Prp. 89 (1898), pp. 24-31 & Same \\
1897 & Statsskattens fordeling 1892/93-1898/99 & New source \\
1898 & Statsskattens fordeling 1899/00-1905/06 & New source \\
1899 & Statsskattens fordeling 1899/00-1905/06 & New source
\end{tabular}


1900 Statsskattens fordeling 1899/00-1905/06

1901 Statsskattens fordeling 1899/00-1905/06

1902 Statsskattens fordeling 1899/00-1905/06

1903 Statsskattens fordeling 1899/00-1905/06

1906 Rygg (1910), p. 50 and 69

1910 NOS VI.57 (1915), p. 29*

1913 NOS VI.57 (1915), p. 30*

1929 Statistisk Årbok 1936, p. 11

1938 Statistiske Meddelelser 1941 (11-12), p. 333

1948 to 1977 See Aaberge and Atkinson (2010)

1978 to 2007

See Aaberge and Atkinson (2010)

2008 to 2011
New source

New source

Revised (new source)

New source

Same

Revised (new source)

Same

Same

Same

Same

Minor adjustment to control total (Revised Accounts)

New data

\section{Table A5. Revised control totals}

\begin{tabular}{lr}
\hline $\begin{array}{l}\text { Control totals for new years, based on Old Definition of Private Income } \\
\text { MNOK }\end{array}$ \\
1892 & 490 \\
1893 & 500 \\
1894 & 503 \\
1895 & 514 \\
1896 & 538 \\
1897 & 560 \\
1898 & 606 \\
1899 & 638 \\
1900 & 668 \\
1901 & 657 \\
1902 & 652 \\
1903 & 648 \\
& \\
2000 & 697332 \\
2001 & 731486 \\
2002 & 789216 \\
2003 & 828107 \\
2004 & 854120 \\
2005 & 918359 \\
2006 & 908676 \\
2007 & 1005373 \\
2008 & 1110046 \\
2009 & 1138789 \\
2010 & 1184684 \\
2011 & 1255926 \\
\hline
\end{tabular}


Table A6. Annual top income shares, all observations

\begin{tabular}{rrrrrr} 
& $10 \%$ & $5 \%$ & $1 \%$ & $0,50 \%$ & $0,10 \%$ \\
\hline 1875 & $40,00 \%$ & $31,74 \%$ & $18,37 \%$ & $14,37 \%$ & $7,89 \%$ \\
1888 & $48,93 \%$ & $36,72 \%$ & $20,53 \%$ & $15,51 \%$ & \\
1892 & $45,95 \%$ & $35,60 \%$ & $20,48 \%$ & $15,91 \%$ & \\
1893 & & $35,26 \%$ & $20,14 \%$ & $15,65 \%$ & \\
1894 & & $35,54 \%$ & $20,52 \%$ & $16,01 \%$ & \\
1895 & & $35,46 \%$ & $20,51 \%$ & $16,03 \%$ & $9,08 \%$ \\
1896 & & & $19,80 \%$ & $15,46 \%$ & $8,79 \%$ \\
1897 & & $34,99 \%$ & $20,35 \%$ & $16,00 \%$ & \\
1898 & & $35,35 \%$ & $20,79 \%$ & $16,42 \%$ & $9,44 \%$ \\
1899 & & $34,69 \%$ & $20,38 \%$ & $16,09 \%$ & $9,21 \%$ \\
1900 & & $34,23 \%$ & $20,18 \%$ & $16,02 \%$ & $9,43 \%$ \\
1901 & & $34,39 \%$ & $19,84 \%$ & $15,66 \%$ & $9,09 \%$ \\
1902 & & $34,60 \%$ & $19,71 \%$ & $15,41 \%$ & $8,90 \%$ \\
1903 & & $34,43 \%$ & $19,46 \%$ & $15,19 \%$ & $8,74 \%$ \\
1906 & $42,19 \%$ & $32,36 \%$ & $17,98 \%$ & $13,99 \%$ & $8,03 \%$ \\
1910 & $31,94 \%$ & $23,15 \%$ & $11,67 \%$ & $8,69 \%$ & \\
1913 & $33,21 \%$ & $23,96 \%$ & $11,61 \%$ & $8,37 \%$ & \\
1929 & $41,32 \%$ & $28,25 \%$ & $12,57 \%$ & $9,06 \%$ & $4,35 \%$ \\
1938 & & $27,56 \%$ & $12,72 \%$ & $9,38 \%$ & $4,56 \%$ \\
1948 & $34,38 \%$ & $22,46 \%$ & $9,10 \%$ & $6,36 \%$ & $2,83 \%$ \\
1949 & $34,02 \%$ & $22,14 \%$ & $8,88 \%$ & $6,20 \%$ & $2,74 \%$ \\
1950 & $34,10 \%$ & $22,09 \%$ & $8,76 \%$ & $6,06 \%$ & $2,63 \%$ \\
1951 & $32,31 \%$ & $20,80 \%$ & $8,16 \%$ & $5,67 \%$ & $2,51 \%$ \\
1952 & $31,39 \%$ & $19,57 \%$ & $6,93 \%$ & $4,59 \%$ & $1,87 \%$ \\
1953 & $33,08 \%$ & $20,49 \%$ & $7,14 \%$ & $4,67 \%$ & $1,83 \%$ \\
1954 & $31,79 \%$ & $19,79 \%$ & $6,86 \%$ & $4,46 \%$ & $1,70 \%$ \\
1955 & $32,61 \%$ & $20,37 \%$ & $7,20 \%$ & $4,76 \%$ & $1,90 \%$ \\
1957 & $32,72 \%$ & $20,94 \%$ & $7,88 \%$ & $5,35 \%$ & $2,35 \%$ \\
1958 & $34,72 \%$ & $21,91 \%$ & $7,76 \%$ & $5,09 \%$ & $2,01 \%$ \\
1959 & $34,20 \%$ & $21,51 \%$ & $7,39 \%$ & $4,73 \%$ & $1,77 \%$ \\
1960 & $32,17 \%$ & $20,06 \%$ & $6,94 \%$ & $4,44 \%$ & $1,62 \%$ \\
1961 & $31,77 \%$ & $19,78 \%$ & $6,76 \%$ & $4,29 \%$ & $1,53 \%$ \\
1962 & $32,20 \%$ & $19,87 \%$ & $6,57 \%$ & $4,11 \%$ & $1,42 \%$ \\
1963 & $32,03 \%$ & $19,67 \%$ & $6,43 \%$ & $3,98 \%$ & $1,35 \%$ \\
1964 & $31,45 \%$ & $19,30 \%$ & $6,28 \%$ & $3,88 \%$ & $1,31 \%$ \\
1965 & $30,65 \%$ & $18,65 \%$ & $5,99 \%$ & $3,69 \%$ & $1,23 \%$ \\
1966 & $31,05 \%$ & $18,89 \%$ & $5,99 \%$ & $3,66 \%$ & $1,20 \%$ \\
1967 & $31,47 \%$ & $19,13 \%$ & $5,95 \%$ & $3,61 \%$ & $1,17 \%$ \\
1968 & $31,31 \%$ & $19,05 \%$ & $5,92 \%$ & $3,58 \%$ & $1,16 \%$ \\
1969 & $31,46 \%$ & $19,21 \%$ & $6,03 \%$ & $3,67 \%$ & $1,21 \%$ \\
& & & & & \\
$1903 \%$ &
\end{tabular}




$\begin{array}{lrrrrr}1970 & 30,29 \% & 18,57 \% & 5,95 \% & 3,66 \% & 1,23 \% \\ 1971 & 30,81 \% & 18,85 \% & 5,99 \% & 3,68 \% & 1,23 \% \\ 1972 & 30,32 \% & 18,48 \% & 5,82 \% & 3,56 \% & 1,18 \% \\ 1973 & 29,60 \% & 18,07 \% & 5,72 \% & 3,50 \% & 1,15 \% \\ 1974 & 28,93 \% & 17,60 \% & 5,56 \% & 3,41 \% & 1,15 \% \\ 1975 & 29,41 \% & 17,73 \% & 5,49 \% & 3,33 \% & 1,09 \% \\ 1976 & 29,73 \% & 17,78 \% & 5,39 \% & 3,23 \% & 1,02 \% \\ 1977 & 30,09 \% & 18,00 \% & 5,45 \% & 3,28 \% & 1,05 \% \\ 1978 & 27,22 \% & 16,28 \% & 4,93 \% & 2,97 \% & 0,94 \% \\ 1979 & 26,58 \% & 15,94 \% & 4,91 \% & 3,01 \% & 1,02 \% \\ 1980 & 25,26 \% & 15,06 \% & 4,60 \% & 2,82 \% & 0,98 \% \\ 1981 & 24,67 \% & 14,71 \% & 4,47 \% & 2,72 \% & 0,94 \% \\ 1982 & 24,36 \% & 14,50 \% & 4,43 \% & 2,72 \% & 0,97 \% \\ 1983 & 24,00 \% & 14,34 \% & 4,42 \% & 2,72 \% & 0,98 \% \\ 1984 & 23,57 \% & 14,13 \% & 4,39 \% & 2,72 \% & 1,00 \% \\ 1985 & 23,64 \% & 14,21 \% & 4,45 \% & 2,77 \% & 1,01 \% \\ 1986 & 23,11 \% & 13,93 \% & 4,37 \% & 2,72 \% & 0,99 \% \\ 1987 & 23,11 \% & 13,96 \% & 4,41 \% & 2,76 \% & 1,01 \% \\ 1988 & 22,73 \% & 13,75 \% & 4,33 \% & 2,69 \% & 0,94 \% \\ 1989 & 21,83 \% & 13,17 \% & 4,13 \% & 2,55 \% & 0,90 \% \\ 1990 & 22,19 \% & 13,47 \% & 4,28 \% & 2,66 \% & 0,93 \% \\ 1991 & 22,27 \% & 13,61 \% & 4,37 \% & 2,72 \% & 0,94 \% \\ 1992 & 23,27 \% & 14,82 \% & 5,38 \% & 3,58 \% & 1,50 \% \\ 1993 & 25,57 \% & 16,90 \% & 6,97 \% & 4,97 \% & 2,40 \% \\ 1994 & 26,91 \% & 17,87 \% & 7,43 \% & 5,30 \% & 2,53 \% \\ 1995 & 26,86 \% & 17,83 \% & 7,36 \% & 5,25 \% & 2,56 \% \\ 1996 & 27,84 \% & 18,65 \% & 7,96 \% & 5,79 \% & 3,00 \% \\ 1997 & 29,09 \% & 19,70 \% & 8,61 \% & 6,31 \% & 3,28 \% \\ 1998 & 27,96 \% & 18,79 \% & 7,99 \% & 5,77 \% & 2,86 \% \\ 1999 & 28,31 \% & 19,19 \% & 8,38 \% & 6,13 \% & 3,11 \% \\ 2000 & 30,45 \% & 21,36 \% & 10,31 \% & 7,89 \% & 4,40 \% \\ 2001 & 26,87 \% & 17,93 \% & 7,36 \% & 5,19 \% & 2,47 \% \\ 2002 & 28,90 \% & 20,15 \% & 9,61 \% & 7,35 \% & 4,16 \% \\ 2003 & 29,82 \% & 21,09 \% & 10,40 \% & 8,03 \% & 4,58 \% \\ 2004 & 31,70 \% & 22,70 \% & 11,62 \% & 9,15 \% & 5,49 \% \\ 2005 & 37,06 \% & 28,13 \% & 16,49 \% & 13,47 \% & 8,25 \% \\ 2006 & 28,22 \% & 18,97 \% & 7,86 \% & 5,56 \% & 2,62 \% \\ 2007 & 28,97 \% & 19,78 \% & 8,54 \% & 6,14 \% & 2,92 \% \\ 2008 & 27,11 \% & 18,34 \% & 7,70 \% & 5,45 \% & 2,49 \% \\ 2009 & 26,95 \% & 17,95 \% & 7,11 \% & 4,88 \% & 2,09 \% \\ 2010 & 27,99 \% & 18,81 \% & 7,74 \% & 5,44 \% & 2,50 \% \\ 2011 & 28,33 \% & 19,02 \% & 7,80 \% & 5,45 \% & 2,44 \%\end{array}$

